\title{
The Morphogenesis of Subchapter C: An Essay in Statutory Evolution and Reform*
}

\section{Robert Charles Clark ${ }^{\dagger}$}

By anyone's reckoning, the law concerning the federal income taxation of corporations and security holders-essentially, subchapter $\mathrm{C}$ of the Internal Revenue Code, ${ }^{1}$ together with its accompanying regulations $^{2}$ and the accumulated body of revenue rulings and case law ${ }^{3}$-is complex. Quite surprisingly for a corpus of rules that is an artificial construct of highly self-conscious human intellects, rather than an attempt to rationalize preexisting social relations, the law exhibits an intricacy approaching that of living systems. The analogy suggests a question. Did the corporate tax law, like a mature organism, have its major traits determined by a set of genes fixed in its infancy, or did it grow in a passive, mechanistic way, its important parts constantly shaped and reshaped in response to the shifting pressures of a changing environment?

The inquiry as to whether corporate tax law be animal or machine may best be advanced by adopting the perspective of a cultural anthropologist. Though "culture" is a term often used to denote a society's total system of symbols, ${ }^{4}$ "a" culture may usefully be defined

* Copyright (C) 1977 by Robert Charles Clark. I am deeply grateful to my colleague, Marvin A. Chirelstein, for encouraging me to attempt the analysis in Part III of this article, and to Bruce Ackerman, Boris Bittker, Scott Boorman, Guido Calabresi, and many other persons for their helpful comments on an earlier draft.

A working draft of Parts I and II of this article was reproduced and distributed in the Harvard-Yale Preprints in Mathematical Sociology series using monies obtained under National Science Foundation Grants Nos. SOC 76-24512 and SOC 76-24394.

$\dagger$ Professor of Law, Yale University.

1. I.R.C. $\S \S 301-385$. Other parts of the Internal Revenue Code also can be considered part of the basic law concerning taxation of corporations. Prominent among these are the accumulated earnings tax provisions, $i d$. $\$ \S 531-537$, and the personal holding company tax provisions, id. $\$ \S 541-547$.

2. Treas. Reg. $\$ \S 1.301-1.383,1.531-1.547$.

3. The basic treatise that explores these materials, as well as the history, purpose, and content of the statutory provisions, is B. Bittker \& J. Eustice, Federal InCome Taxation of Corporations and Shareholders (3d ed. 1971 \& Supp. 1977, No. 2) [hereinafter cited as BitTker \& Eustice]. A useful collection of cases, together with extensive notes on other cases and rulings, is II S. Surrey, W. Warren, P. McDaniel \& H. Ault, Federal Income Taxation: Cases and Materials (1973) [hereinafter cited as Surrey \& WARren]. Current developments, as well as other materials, are digested in [1977] 3 Stand. Fed. TAX ReP. (CCH) IT 2300-2595.01 (1976).

4. E.g., C. GeERTz, Thick Description: Toward an Interpretive Theory of Culture, in The Interpretation of Cultures 3 (1973) (expounding semiotic theory of culture). 
as any unified complex of meanings learned and shared by members of a human group. More specifically, the printed lore concerning corporate taxation-the statutes, regulations, rulings, lawyers' opinions, judicial opinions, treatises, and articles-can properly be viewed, in the same spirit as the anthropologist contemplates prehistoric pots and vases, as a collection of related "cultural products" that furnish insight into the structure of a particular society. Similarly, the elaborate behavior of taxpayers, lawyers, revenue agents, courts, and legislators in connection with these cultural products can be understood as "cultural activities," a source of scientific puzzlement to the outside observer trying to discern their various instrumental, ritualistic, and expressive aspects. These cultural products and cultural activities together form an operational definition of "the corporate tax culture."' It is an important culture that has comparatively clear boundaries.

With this conceptual framework, the metaphorical question whether the corporate tax culture be animal or machine may be unpacked into several nonmetaphorical and more precise queries. ${ }^{6}$ Of urgent interest to the anthropologist is whether a given culture can be understood in terms of a few fundamental ideas or themes, rather than as a disordered manifold of particular products and activities that resists any attempt at reduction. This is not a question about the history of a culture, though history may be one source of clues to the answer. A second crucial task for the social scientist is to determine the scientifically lawful character of cultural evolution. Does a given culture change in a progressive, cumulative way (as medical knowledge certainly does in our own society); in a cyclical fashion (as do the fine arts, with alternating periods of classicism and romanticism arguably leading only to one another); in a random way (as does a sequence of stock prices in an efficient neoclassical market); or in accordance with some other model? A third and related question concerns the relationship

5. For introductions to the concept of culture, see A. Kroeber, Anthropology: Culture Patterns and Processes 60.64 (Harbinger Books ed. 1963); F. Merrill, Society And Culture 79-83 (4th ed. 1969); J. Spradley \& D. McCurdy, Anthropology: The Cultural Perspective 4-6 (1975). These discussions should indicate that the definitional approach used in the text is not far away from the center of a very large conceptual circle.

6. See generally A. Kroeber, supra note 5, at 64-73, 152-82, 194-226, 233-37 (discussing nature of cultural processes and patterns of cultural change).

7. A well-known example of a cumulative view of evolution in human affairs is the Weberian hypothesis of a process of rationalization first generated by the advances of theoretical science, then spreading to technology, insinuating new rational imperatives in social organization, and pressuring for changes in ideologies, philosophies, religious beliefs, and the expressive cultural system. See T. Parsons, The Social System 505-20 (1951). The most striking confirmation of the thesis was developed in Weber's paper on the growth of rationalization in music. M. Weber, The Rational and Social Foundations of Music (D. Martindale, J. Riedel \& G. Neuwirth trans. 1958). 
of cultural changes to developments in other spheres of human activity. Often enough, it is conceptually possible to distinguish cultural changes generated internally from those catalyzed by external political, economic, and technological events. Are cultural changes independent of such other developments? If not, what are the causal connections? Alternatively, are changes in all traditionally conceived spheres of activity roughly correlative and reflective of some more basic realities? Realistically, of course, this third question is one of degree: to what extent do cultural changes occur endogenously, as an unfolding of the logic of the cultural scheme itself?

The thesis tendered in this article is that definite answers to each of the posited questions emerge from a study of the corporate tax culture. First, the present highly developed law of the taxation of corporations and shareholders is the product of a few basic decisions. These decisions established principles that account for many important aspects of the law, though not, of course, for all its details. ${ }^{9}$ Second, the corporate tax culture has developed from these principles in a cumulative, evolutionary way rather than in a cyclical or random manner. This cumulative evolution displays two important features. It has had a fairly constant direction, and that direction has been toward legal rules of ever-increasing complexity and specificity. ${ }^{10}$ Finally, the

8. What is endogenous to a process of change is, of course, a function of the definition of the process, which may be clearer in some contexts than others. One study, roughly analogous to the effort here, found that the strikingly parallel development of social security and welfare programs in Britain and Sweden resulted primarily from the influence of administrative bureaucracies learning from experience with past programs and accordingly adjusting and elaborating (rather than redirecting) policies within a basic liberal framework; factors such as socio-economic development, elections, political parties, and interest groups were of secondary importance. H. Heclo, Modern Social Policies in Britain and Sweden 284-304 (1974). The author concluded that social politics could best be viewed as a learning process, rather than as a mere expression of conflicting interest groups or power relationships. Id. at 304-22. Such a view emphasizes endogenous forces of change.

9. As the article approached completion, I was informed that E. Allan Farnsworth made a strikingly similar claim about the law of contract remedies. In an excellent article, he asserted that "there were seven critical choices, and that from these the reader who has the patience to work through the analysis can deduce the bulk of the law of contract remedie $\rightarrow$ Farnsworth, Legal Remedies for Breach of Contract, 70 Colum. L. Rev. 1145, 1145 (1970).

10. Some persons may despondently assume that law is always becoming more complicated. But to assert that an area of law evolves fairly constantly and cumulatively toward complexity is not an obvious, universal, or contentless proposition. Great changes in doctrine may occur without one's being able to perceive clear, substantial differences in complexity of doctrine at any given phase. See, $e \rightarrow$ James, Proof of the Breach in Negligence Cases (Including Res Ipsa Loquitur), 37 VA. L. REv. 179, 198-99 (1951) (shift in tort law from negligence to res ipsa loquitur to strict liability). More strikingly, legal change is not infrequently toward simplification. Examples in tort law are the modern cases abolishing various charitable, familial, and governmental immunities. See, e.g., M. 
corporate tax culture is, to a surprising degree, of endogenous origin. The pressures created by its own basic postulates have controlled its development. To return to the metaphorical question-whether corporate tax law be animal or machine-it seems clear that the biological metaphor is more apt.

The task of reducing the law of corporate taxation to a few basic principles and tracing their direct and interactive effects serves three distinct purposes. The first is academic. The immediate objective of showing how basic decisions control later developments is to supply hypotheses about cultural evolution; the pattern found here may stimulate related research and theoretical exploration into the evolutionary processes of other branches of the law. The second purpose of this reductive effort is intensely and narrowly practical. A synthesis of corporate tax law ordered in terms of basic axioms should greatly facilitate-for students, lawyers, judges, and others dealing with the tax law-the recall, understanding, and use of a multitude of particular rules. Finally, and perhaps most importantly, the present study should promote rational tax reform. An axiomatic synthesis of corporate tax law suggests a systematic approach to major revisions: posit changes in each basic principle, trace their probable effects on the Code and on the case law ramifications of the actual decision, and evaluate the result; then posit combinations of changes and continue the process. This approach, unlike the hit-or-miss technique of debating the merits of the intuitively obvious and apparently salient consequences of isolated reform proposals, would identify clearly the most important legal effects of major reform options. In addition, it would make more specific some of the a priori reasons for expecting certain economic consequences to flow from specific changes. Because of its emphasis on probable changes in the legal culture-each of which has its associated level of costs-the method would provide, at the very least, a needed supplement to economic analyses that focus only on the supposed macroeconomic effects of various reforms.

Part I of this article comments briefly on the dynamics of the development of the corporate tax culture, as a useful preface to the exegesis of the basic cultural principles. Part II then presents these principles and uses them to explain the major features of the present tax law. This exercise will lend strong indirect support to the claim

Franklin, Injuries and Remedies: Cases and Materials on Tort Law and Alternatives 227-50 (1971). Another example is the abolition of separate specifications of the duties of owners and occupiers of land to trespassers, licensees, and invitees, and the substitution of a more general negligence standard. See, e.g., Rowland v. Christian, 69 Cal. 2d 108, 443 P.2d 561, 70 Cal. Rptr. 97 (1968). 
that the culture has evolved endogenously, for the explanation of numerous complex problems and their legal solutions will be accomplished-convincingly, I hope-without reference to changing political or economic conditions. Enough history is included merely to suggest the cumulative progression toward greater legal complexity, a progression that most tax scholars and practitioners would likely concede to be virtually self-evident. Greater historical detail might obfuscate the explanatory effort, which is premised upon the simplicity of the basic relationships among the handful of key principles and the multitude of particular tax rules and judicial decisions. Afterwards, Part III explores the utility of the explanatory scheme for the expedition of tax-reform efforts by considering the likely consequences of changing one or more of the basic decisions in various ways. It also offers a combination of changes that constitutes a promising reform package.

\section{The Dynamics of Development}

The evolution of the corporate tax culture displays a recurrent pattern of particular events: when a new legal rule is prescribed, there follows a continual process of related tax-avoidance efforts by taxpayers and counter-responses by the Internal Revenue Service, which leads to the formulation of more specific and more complex rules. Examination of this pattern will clarify the sense in which the development of the corporate tax culture has been endogenous. ${ }^{11}$ Clearly, the hypothesis that the culture is a largely closed system evolving in a preordained way cannot be pressed to extremes. No real system, short of the universe, is totally self-contained. Or, if there is such a system, ex hypothesi we will never know about it. Yet the evolution of the corporate tax culture is sufficiently separable from the chief external forces acting upon it that much can be understood without a detailed knowledge of variations in those forces. ${ }^{12}$

The principal internal forces that have shaped the corporate tax culture derive from the motivations and aspirations of its different groups of participants. Each group-taxpayers, the Service, courts, and

11. This article focuses principally upon the evolution of ideas. There might be a differently patterned process of evolution for specific social and institutional arrangements connected with corporate tax law-the composition and distribution of the tax bar and other groups of corporate tax advisers (such as accountants), the internal organization of the relevant parts of the Internal Revenue Service, and so forth.

12. Perhaps one of the things that has frustrated social scientists most regularly is the perception that most social systems, as compared to physical systems, display a much lower degree of independence. The corporate tax culture provides a welcome exception to this generalization. 
legislators-displays characteristic behavioral tendencies that are themselves cultural activities and part of the corporate tax culture as defined. They are therefore endogenous. These tendencies, however, are factors distinct from the basic tax principles later invoked as explanatory tools. By themselves, abstract principles cannot develop into a culture. In this obvious sense, corporate tax law has not been a mere unfolding of the logic of its postulates. The more interesting and instructive point, though, is that one can understand the development of the law with little knowledge of actual variations in the strength or direction of the participants' behavioral tendencies. Moreover, although an adequate account of the causes of these tendencies would force a resort to considerations exogenous to the corporate tax culture -such as theories of psychology or political science-these causal explanations would be more relevant to a desire for intellectual completeness or for greater confidence that the behavioral tendencies exist than to explaining and predicting actual developments in the tax law. This irrelevance of different theories of motivation forms another aspect of the endogenous character of the evolution of the corporate tax culture.

The principal actors within the corporate tax culture are taxpayers and the Internal Revenue Service. Taxpayers and their lawyers continually seek to discover, invent, and exploit ways of reducing their taxes. The plethora of schemes to effect "bailouts"13 is a striking illustration of this tendency. The Internal Revenue Service continually counters these new modes of tax reduction. Courts and Congress arbitrate the conflicts between the principal actors and function as shapers of the cultural environment. But their specific behavioral tendencies diverge.

Courts tend to resolve conflicts in terms of open-ended judicial policies and rules. ${ }^{14}$ Their behavior may be understood as a form of adherence to ideals concerning the proper role of the judiciary, as a way of preserving and increasing their power, or in some other way; for present purposes, the cause of the tendency is of secondary impor-

13. "Bailout" is a term of art in the corporate tax culture; its meaning is not always clear. In this article, the term denotes a scheme by shareholders to extract corporate earnings at capital gains tax rates, that is, to avoid the higher ordinary income tax presumptively applicable to income distributed by the corporation to its shareholders. See p. 105 infra. In addition to pointing out an unquestionably legitimate form of bailout, this article will isolate three categories of problematic bailouts that have played important roles in the evolution of the corporate tax culture. See pp. 113, 118, 132 infra.

14. See, e.g., pp. 122-23 infra (creation of business purpose doctrine by courts faced with "divisive bailouts"). 
tance. By contrast, Congress, when bidden by taxpayers or the Service to resolve conflicts, often seeks to give the successful bidders more certainty. It tends to exercise its power in resolutions couched in mechanical rules that superficially appear to reduce both judicial discretion and, perhaps, the prelitigation discretion of the losing bidders for congressional favor. ${ }^{15}$ "Mechanical rules" means rules that might be programmed into a computer or robot to produce determinate answers from an input of neutrally described yet relevant facts. In a sense, Congress often legislates with an eye toward the needs and capacities of such a "reasonable robot." Very rarely is a rule completely or successfully mechanical, of course, but this should not blind us to the existence of statutory aspirations toward mechanism.

The thesis that courts and Congress have different tendencies seems to comport with many, though not all, of the major historical developments discussed in this essay. ${ }^{16}$ But even if it were not true, the evolution of corporate tax law would have been toward more specific rules as new, unforeseen experiences confronted the initially formulated general rules. Legal change, at least under a fairly new statutory regime having no common law antecedents, seems inevitably to progress in such fashion. Developments in the wake of fresh, specific corporate tax rules support this hypothesis. ${ }^{17}$

The one major qualification to the picture of endogenous evolution thus far presented is that the speed and magnitude of developments in the corporate tax culture undoubtedly are affected by changes in tax rates. These in turn depend upon political forces. But such matters must be left to the econometrician. Lawyers and anthropologists may yet have an interest in morphogenesis, the development of formchanges in legal doctrine and patterns of behavior.

\section{Evolution of the Corporate Tax: Elements and Consequences}

Contemporary corporate tax law may be traced to seven basic decisions or principles. ${ }^{18}$ The first two created the so-called "double tax"

15. See, e.g., p. 112 \& note 91 infra (describing Congress's response to judicial "morass" created by courts' attempts to specify tax treatment of redemptions); p. 120 infra (describing Congress's response to "preferred stock bailout").

16. Exceptions to the tendencies appear at p. 103 infra (noting open-ended character of Congress's original accumulated earnings tax provisions) and at note 147 infra (describing Congress's provision that "boot" received by shareholders in reorganization be taxed at ordinary rates if transaction has "effect of the distribution of a dividend").

17. See, e.g., p. 103 infra (development of present accumulated earnings tax provisions); p. 112 infra (development of present tax treatment of redemptions).

18. Some of the seven principles enumerated here could be reduced to more discrete axioms. See, e.g., pp. 100-04 infra (distribution principle); pp. 107-17 infra (corporate veil principle). Others, such as the second (distribution) and fourth (dividend), see pp. 100- 
system; the next three relate to the special treatment for capital gains; the final two concern a general and a special nonrecognition policy.

Each principle will first be placed in its relevant historical context. A discussion of its cultural consequences will follow. It will be observed that the more baroque phenomena, those which typically preoccupy the corporate tax practitioner, do not emerge until one has proceeded well into the list. Indeed, one can predict that the interest of the economist will wane, and that of the tax lawyer wax, as the explication progresses.

\section{There shall be a separate tax on corporate income (The separate tax principle)}

Congress made the crucial decision to impose a separate corporate income tax in $1909,{ }^{19}$ apparently without a principled assessment of the wisdom of such a move. ${ }^{20}$ The absence of reasoned debate over this core cultural principle is not surprising. The tax rate was low, one percent of net income in excess of $\$ 5000^{21}$ as compared with today's marginal rate of forty-eight percent, ${ }^{22}$ and economic science was less advanced and less widely taught than it is today. Arguing about misallocations of resources would have reaped little political profit. Furthermore, there was no individual income tax in $1909^{23}$ and thus

04, 106-07 infra, or the third (capital gains) and fourth (dividend), see pp. 104-07 infra, could be combined. The principles might be grouped historically as well. Additional principles might conceivably be adduced. See, e.g., p. 107 infra (different tax treatments for corporate payments to debtholders than for corporate payments to shareholders). The seven principles as formulated in this article represent the author's choice of a convenient conceptual grouping and ordering that serves to illustrate the interaction among principles and the resulting growth in doctrinal complexity.

19. Payne-Aldrich Tariff Act of 1909, ch. 6, $\S 38,36$ Stat. 112. The federal government has taxed corporate income continuously ever since. It had been taxed even earlier, by the income tax of 1894 , but the Supreme Court declared unconstitutional the entire statute of which this corporate tax was part. Pollock v. Farmers' Loan \&. Trust Co., 158 U.S. 601, 637 (1895) (on rehearing). The tax is today imposed by I.R.C. $\S 11$.

20. The legislative history of the 1909 statute bears no indication that Congress seriously explored the advisability of the separate tax. Carlton Fox, in his massive compilation of documents relating to the Revenue Acts of 1909 to 1948, notes that the "reports on the Tariff Act of 1909 are omitted, as they have no relevance to Section 38 of the act, which comprises the provisions of the Corporation Excise Tax Act of 1909." 1 Revenue Acts of 1913, 1914, 1916: Law, Reports, Miscellany at tab "1909" (Carlton Fox compil. 1948). Seidman, who, unlike Fox, also considered congressional floor debates, produces nothing on point. J. Seidman, Seidman's Legislative History of Federal InCOME TAX LAWs 1938-1861, at 1009-11 (1938).

21. Payne-Aldrich Tariff Act of 1909 , ch. 6, $\S 38,36$ Stat. 112.

22. For taxable years ending after December 1, 1974, and before January 1, 1979, the rate is $20 \%$ of the first $\$ 25,000$ of a corporation's taxable income, $22 \%$ of the next $\$ 25,000$, and $48 \%$ of the excess. I.R.C. $\S 11$.

23. Until the adoption of the Sixteenth Amendment in 1913, constitutional barriers prevented imposition of an individual income tax. See Pollock v. Farmers' Loan \& Trust Co., 158 U.S. 601 (1895) (on rehearing) (individual income tax levied by Congress in 1894 invalidated as integral part of unconstitutional tax statute). 
no reason to foresee the problem of a "double tax" on corporate-source income, that is, one that falls both at the corporate and shareholder levels.

Obviously, without the separate tax principle the corporate tax culture as we know it would not exist. Under an alternative system-for example, one that simply taxed shareholders on corporate income when distributed to them or when realized in a stock sale, or one that taxed them as partners, on all current corporate income, whether or not distributed-some of the issues explored in this essay would have arisen, but the overall shape of the law would be very different. In addition, the separate tax principle has spawned three more specific sets of cultural consequences, none of which was contemplated in 1909.

First, since partnerships and proprietorships are not subject to the separate tax, ${ }^{24}$ the principle has led to an enormous amount of planning and litigation focused upon the operational forms of business enterprises. ${ }^{25}$ Judges were called upon to decide whether entities denominated trusts or partnerships were corporations in substance and to enunciate the factors that distinguish these forms of organization. ${ }^{26}$ Taxpayers attempted to construct business forms, such as limited partnerships, that would achieve the nontax advantages of the corporate form without sacrificing the benefits of partnership taxation. In response, the Service engaged in selecting and expounding judicial criteria and promulgating mechanical rules of classification. ${ }^{27}$ Congress, however, has yet to embark on its own attempt to mechanize this sector of the tax culture.

The separate tax principle has also created incentives to lobby for

24. Generally, a partner is taxed individually on his distributive share of the partnership's income, gains, or losses, regardless of whether any income is in fact distributed to him. See I.R.C. $\$ \S 701-705$. Proprietors are treated as individuals for tax puiposes.

25. See, e.g., Bittker \& Eustice, supra note 3, at 1-24 to 1-27, 2-1 to 2-26; id. (Supp. 1977, no. 2) at S2-1 to S2-10; SURrey \& WARREN, supra note 3, at 139-52; Miller, Choice of the Form of Business Organization, in Lectures on Taxation of Business EnTERPrise 297 (1952).

References to entire chapters of books or to blocks of annotations appear in this and other footnotes. These citations are geared to illustrating the evolution of the corporate tax culture. To borrow an idea from the hearsay rule, sources will often be cited not to prove the validity of legal points, but simply to prove that sources exist-i.e., that certain tensions in the basic principles have in fact given rise to legal-cultural "products."

26. The leading case is Morrissey v. Commissioner, 296 U.S. 344 (1935) (business trust treated as "association" taxable as corporation).

27. Treas. Reg. $\$ \S 301.7701-1,-2(a)$ to $-2(e)$ (1967, as amended 1974, 1975). The criteria are obviously based on factors discussed in Morrissey v. Commissioner, 296 U.S. 344 (1935), see note 26 supra. These regulations were issued in 1960 in the wake of court decisions against the Service in the professional association area. See SURRey \& WARren, supra note 3 , at 95 . 
special relief legislation. The most striking of the successful lobbying efforts is subchapter $\mathrm{S},{ }^{28}$ which allows specified corporations to elect exemption from the separate corporate tax. ${ }^{29}$ The income of a qualifying corporation is taxed only to its shareholders. ${ }^{30}$ Despite the basic simplicity of the subchapter $\mathrm{S}$ concept, its implementation in 1958 bred a burgeoning body of relevant lore-over 130 cases and 60 Service rulings, many of them due to the statute's restrictiveness and its unclear but numerous provisions. ${ }^{31}$

Finally, the separate corporate tax has had a substantial impact on business behavior, though there is disagreement on the magnitude and precise nature of its influence. The cultural products of this phenomenon include a substantial literature concerning the alleged misallocation of resources and inequities among taxpayers caused by the separate $\operatorname{tax}^{32}$ a collection of inconclusive theoretical and empirical studies dealing with the incidence of the corporate tax, ${ }^{33}$ and numerous

28. I.R.C. $\$ \S 1371-1379$. A major purpose of subchapter $S$ was to aid small businesses by eliminating the inequitably heavy burden that the corporate tax could impose upon lower-bracket shareholders with marginal tax rates lower than the flat corporate rate. See S. ReP. No. 1983, 85th Cong., 2d Sess. 87 (1958) (subchapter S designed to allow taxpayers to elect business form without considering tax factors and to aid small businesses whose shareholders had marginal tax rates below corporate rate). Similar motivations produced I.R.C. $\S 1244$, which allows the decline in value of shares of stock in certain small businesses to be treated as ordinary rather than capital loss. See H.R. REP. No. 2198, 85th Cong., 2d Sess. 4 (1958) (discussing purposes of encouraging outside investment in small business by reducing risk of loss and eliminating inequity of allowing partnerships and proprietorships, but not small business corporations, to deduct losses as ordinary loss). See also Moore \& Sorlien, Adventures in Subchapter S and Section 1247, 14 TAX L. REv. 453 (1959).

29. This special treatment is, of course, quite restricted. For example, only corporations with 10 or fewer shareholders, who in most cases must be individuals, can qualify. See I.R.C. $\$ \S 1371(a), 1372(a)$.

30. Id. $\S 1372(\mathrm{~b})$.

31. See generally I. Grant, Subchapter S Taxation (1974). The figures in the text may be found in the printed advertisements used by the book's publisher to convince tax practitioners of the need for a special treatise. See also BITTKER \& Eustice, supra note 3, at 6-1 to 6-38; id. (Supp. 1977, no. 2) at S6-1 to S6-15; Surrey \& WARren, supra note 3, at 555-74; Annot., [1977] 7 Stand. Fed. TaX Rep. (CCH) If 4845-4847M (1976).

32. See, $e \rightarrow$ McLure, Integration of the Personal and Corporate Income Taxes: The Missing Element in Recent Tax Reform Proposals, 88 HARv. L. Rev. 532, 540-41 nn.42, 43, \& 44 (1975) (citing sources).

33. See, e.g., M. Krzyzaniak \& R. Muggrave, The Shifting of the Corporate Income Tax (1963); R. Musgrave \& P. Musgrave, Public Finance in Theory and Practice 415-29 (2d ed. 1976); J. Pechman \& B. OKner, Who Bears the Tax Burden? (1974) (incidence of several forms of taxation, including corporate); Cragg, Harberger \& Mieszkowski, Empirical Evidence on the Incidence of the Corporation Income Tax, $75 \mathrm{~J}$. Polirical Econ. 811 (1967); Goode, Rates of Return, Income Shares, and Corporate Tax Incidence, in EFfeCts of Corporation Income Tax 207 (M. Krzyzaniak ed. 1966); Gordon, The Incidence of the Corporation Income Tax in U.S. Manufacturing, 1925-1962, 57 AM. EcoN. REv. 731 (1967); Gordon, Incidence of the Corporation Income Tax in U.S. Manufacturing: Reply, 58 Am. Econ. Rev. 1360 (1968); Harberger, The Incidence of the Corporation Income Tax, 70 J. Political Econ. 215 (1962); Krzyzaniak \& Musgrave, Incidence of the Corporation 
reform-oriented proposals suggesting alternatives to a separate corporate $\operatorname{tax} .^{34}$

2. A shareholder-level tax on corporate income shall be imposed, but generally only upon its distribution to shareholders (The distribution principle)

The distribution principle has three analytic components. The first is that distributions from the corporation to the shareholders can be income taxable to the shareholders. This notion derives from the first valid act imposing a federal individual income tax, the Revenue Act of 1913, which listed "dividends" (an undefined term) among the things included in the term "income." 35 Apparently, this inclusion was an undebated reflex action based on a commonsensical understanding of the concept of income.

The second aspect of the principle is that only corporate "income" is subject to a shareholder-level tax: distributions fairly taxable to shareholders should come from the corporation's current or retained earnings. The underlying rationale is that a distribution to shareholders that in substance consists merely of a return of capital originally contributed by those shareholders should not be considered gain, much less taxable income. This idea, not explicit in the 1913 statute, soon received legislative clarification in the stipulation that "dividends" are distributions "out of [the corporation's] earnings and profits." ${ }^{36}$ Note that this treatment entails lifting the corporate veil to some extent, for the tax treatment of the shareholders receiving a dis-

Income Tax in U.S. Manufacturing: Comment, 58 AM. Econ. Rev. 1358 (1968); McLure \& Thirsk, A Simplified Exposition of the Harberger Model II: Expenditure Incidence, 28 Nat'L Tax J. 1, 195 (1975); Mieszkowski, Integration of the Corporate and Personal Income Taxes: The Bogus Issue of Shifting, 31 Finanzarchiv 286 (1972); Mieszkowski, Tax Incidence Theory: The Effects of Taxes on the Distribution of Income, $7 \mathrm{~J}$. Econ. LiT. 1103 (1969); Slitor, Corporate Tax Incidence: Economic Adjustments to Differentials under a Two-Tier Tax Structure, in Effects of Corporation Income Tax 136 (M. Krzyzaniak ed. 1966).

34. See, e.g., McLure, supra note 32, at 549-80 (excellent discussion of alternative schemes to integrate corporate with individual income tax); Special Report: Carter's Tax Plan, Bus. WeEk, Aug. 29, 1977, at 46, 55-56 (predicting that Carter Administration will propose partial integration of corporate with personal income tax).

35. Revenue Act of 1913, ch. 61, $\$$ IIB, 38 Stat. 167 (current version at I.R.C. $\S 61$ ).

36. The original 1916 statute provided that any distribution made "out of [corporate] earnings or profits" accrued since March 1, 1913, would be deemed a dividend-taxable, of course, at ordinary rates. Revenue Act of 1916, ch. 463, $\S 2$ (a), 39 Stat. 757 (current version at I.R.C. $\$ 316(a)(1))$. A 1917 addition specified the priority rule that a distribution is deemed to come out of the corporation's most recently accumulated earnings. Revenue Act of 1916, ch. 63, § 31(b), added by 40 Stat. 338 (1917). Since 1936, distributions out of earnings and profits of the taxable year have been considered taxable dividends even if the accumulated earnings and profits account shows a deficit. Revenue Act of 1936, ch. 690, § 115, 49 Stat. 1687 (current version at I.R.C. $\$ 316(a)(2)$ ). Currently, I.R.C. 
tribution depends in part on tax-accounting attributes of the corporation itself. Though the notion seems conceptually unproblematic, it has created interpretive and administrative problems. ${ }^{37}$

The third and by far the most important aspect of the distribution principle is that undistributed corporate income is not generally taxable to shareholders. This point was not explicit in the 1913 act but was clearly implied;38 it was also discussed in Congress. ${ }^{39}$ A few years later the Supreme Court expressly recognized it. ${ }^{40}$ The decision not to tax shareholders on undistributed corporate income was tied not to any specific economic policies or political goals but to the conceptual argument that gain in the value of property, that is, gain that has not yet been realized, should not be taxed as income. To apply this "realization" requirement of general income tax law to undistributed corporate income, one must view the corporation as separate from its shareholders; otherwise, it would seem that taxable gain realized by the corporation has been sufficiently realized for tax purposes by the shareholders, who have the residual claim to corporate earnings. Here,

$\$ 316(a)$ defines dividends as distributions out of current or accumulated earnings and profits and goes on to provide that, except as otherwise provided in the Code's subtitle on income taxes, every distribution is deemed to be out of earnings and profits to the extent thereof.

The treatment of distributions at the shareholder level is set forth in I.R.C. $\$ 301$; subsection 301(c) makes it clear that distributions are first to be treated as dividends to be included in (ordinary) gross income, and that only after the corporation's earnings and profits account has been entirely depleted may a distribution be treated as a return of capital or capital gain. As noted in the text, the earnings and profits requirement means that a limit is placed on the extent to which the law views the corporation as a separate entity; it is not the case that all distributions are dividends, but only those out of corporate earnings. The requirement thus cuts against the tendency, displayed in the first principle and various aspects of the second and fifth principles, to reify the corporate entity. See pp. 97-100 supra; pp. 108-10 infra.

37. See genera $\rightarrow$ Andrews, "Out of its Earnings and Profits": Some Reflections on the Taxation of Dividends, 69 HaRv. L. REv. 1403 (1956) (arguing that requirement has outlived its usefulness).

38. The implication appears in the provision that penalizes the accumulation of earnings for the purpose of evading the individual tax. Revenue Act of 1913, ch. 16, § IIA, 38 Stat. 166.

39. See 50 Cong. Rec. 3774-75, reprinted in J. Seidman, supra note 20, at 984-85 (Sens. Root and Williams).

40. In Lynch v. Hornby, 247 U.S. 339, 343 (1918), Justice Pitney clearly articulated the distribution principle in explaining the intended difference in treatment between a shareholder's undivided interest in the profits and his participation in dividends declared and paid. That undistributed corporate income was not considered income to shareholders is also apparent from Towne v. Eisner, 245 U.S. 418 (1918), which held that a stock dividend, because it takes nothing from the company and gives nothing to the shareholders but rather changes only the evidence of their ownership interests, was not "income" under the 1913 statute. Undistributed corporate income not even subject to a change in the paper evidence of claims against it is a fortiori not income to shareholders. Cf. Eisner v. Macomber, 252 U.S. 189 (1920) (common stock dividend paid on common stock not "income" within meaning of Sixteenth Amendment). 
in contrast to the second aspect of the distribution principle, the corporate veil is respected.

The separate tax principle and the distribution principle together create a "double tax" on currently distributed corporate income; ${ }^{41}$ they impose an onerous tax at both the corporate and the shareholder levels. Taxpayers, of course, wish to escape this double taxation. Two basic avoidance strategies are available. One is to cast corporate distributions in the guise of something other than dividends. In a close corporation, for example, the shareholders' salaries as officers may be inflated to eliminate earnings and hence formal dividends. This disguised dividend strategy is discussed further in connection with the fourth principle, ${ }^{42}$ which adds to taxpayers' incentives to use it. It is a common belief among tax lawyers that many close corporations can and do nullify the double tax in this manner.

The second basic strategy is to delay the extraction of corporate earnings. The retained earnings strategy rests on the pivotal third aspect of the distribution principle. Shareholders often can control the retention or disbursement of corporate earnings and hence can avoid the double tax simply by retaining earnings instead of distributing them..$^{43}$ At the least, they can reap the benefit of deferring the shareholder-level tax. Frequently, they can do even better, if they incorporate the fifth principle into their strategy. ${ }^{44}$ The significant point here is that the retained earnings strategy, with the help of certain subsequent principles, enables taxpayers not only to avoid double taxation but also to achieve a tax level lower than that of comparable sole proprietors or partners. ${ }^{45}$

There is, then, an incentive to retain earnings even though nontax business considerations might not indicate this course of action. Predictably, taxpayers have responded to the incentive. ${ }^{46}$ Equally pre-

41. The shareholder-level tax, of course, does not literally double the tax burden, for it applies only to distributed earnings, which necessarily are net of corporate taxes.

42. See pp. 106-07 infra.

43. Assume, as will all the numerical examples in the footnotes of this article (unless otherwise indicated), a corporation with a marginal tax rate of $48 \%$ and a sole shareholder with marginal tax rates of $70 \%$ for ordinary income and $25 \%$ for net long-term capital gains. If the corporation earns an additional $\$ 100$ and distributes the after-tax amount as a dividend, the current tax burden is $\$ 84.40-i . e ., \$ 48$ to the corporation and .70 (\$52), or $\$ 36.40$, to the shareholder. This tax pattern may be called the "corporate overtax model." If the earnings are retained, the current tax burden is $\$ 48$. As for potential tax liability in the latter situation, see note 81 infra.

44. See pp. 107-17 \& note 81 infra.

45. If the shareholder in note 43 supra operates his business as a sole proprietor or partner, the additional $\$ 100$ of business income would suffer a tax burden of $\$ 70$. This is the "proprietorship model" of taxation. See note 24 supra.

46. See Blume, Crockett \& Friend, Stockownership in the United States: Characteristics and Trends, Survey of Current Bus., Nov. 1974, at 18. 
dictably, the courts and Congress have elaborated the law in an effort to make successful avoidance techniques more difficult to consummate. The chief cultural results are the complicated accumulated earnings $\operatorname{tax}^{47}$ and personal holding company tax provisions ${ }^{48}$ and the large accretion of related judicial decisions. ${ }^{49}$

The accumulated earnings tax provisions impose a stiff penalty tax on every corporation "formed or availed of for the purpose of avoiding the income tax with respect to its shareholders ... . by permitting earnings and profits to accumulate instead of being divided or distributed." 50 Accumulation of earnings "beyond the reasonable needs of the business" presumptively establishes illicit purpose. ${ }^{51}$ The present provisions can be traced to a short clause in the Revenue Act of $1913 .^{52}$ Thus in contrast to its performance in connection with most of the other basic decisions, Congress seems here to have foreseen, at least dimly, a major and recurrent problem that would result from the principles it was establishing. In 1921, the "reasonable needs of the business" criterion and the approach of penalizing the corporation rather than taxing shareholders as if they had received dividends were first adopted, ${ }^{53}$ and this basic pattern continues.

But the legislation did not halt the evolutionary process, for the open-ended references to improper purpose and business needs have resulted in numerous legal decisions, most of which are heavily factdependent and of scant use as precedents. ${ }^{54}$ Congress, in a bid to mitigate the horrors of the swamp of case law, eventually moved to enlarge, complicate, and mechanize the statutory provisions, as a comparison of those in the 1954 Code $^{55}$ with those in the 1921 Code $^{56}$ will show. In the former, but not the latter, appears an involved definition of "accumulated taxable income" 57 and special burden-of-proof

47. I.R.C. $\$ \$ 531-537$.

48. Id. $\S \S 541-547$.

49. See Annot., [1977] 4 Stand. Fed. Tax Rep. (CCH) If 3300-3321, 3325-3348 (1976).

50. I.R.C. $§ 532(a)$.

51. Id. $\S 533(\mathrm{a})$. If the Service establishes that earnings have been accumulated "beyond the reasonable needs of the business," the corporation must disprove its allegedly illicit purpose by a preponderance of the evidence.

52. The Revenue Act of 1913 provided that if a corporation was "formed or fraud. ulently availed of" to escape the individual income tax by permitting profits to accumulate, each shareholder would be taxed on his ratable share of profits, whether or not distributed. Revenue Act of 1913, ch. 16, $\$$ IIA, 38 Stat. 166.

53. Revenue Act of 1921, ch. 136, $§ 220,42$ Stat. 247.

54. See Bittker \& Eustice, supra note 3, at 8-3. See generally id. at 8-1 to 8-27.

55. I.R.C. $\$ \$ 531-537$.

56. Revenue Act of 1921 , ch. 136, $\S 220,42$ Stat. 247. The 1921 Code expanded the 1913 provisions. See note 53 supra.

57. I.R.C. $§ 535$. 
rules. ${ }^{58}$ Nonetheless, it is extremely doubtful that the accumulated earnings tax provisions have had any significant tendency to curtail the widespread use of the retained earnings strategy. The statute normally requires proof of reasonable business needs-a difficult task. Moreover, investors in public corporations can easily and blamelessly avoid its thrust. Those whose tax brackets make the strategy highly desirable may invest in corporations that retain most of their earnings for good business reasons; others may prefer companies with higher dividendto-earnings ratios. The retained earnings strategy remains optional, because investors can choose and switch companies instead of trying to force managements to make economically unwise accumulations.

The personal holding company tax provisions deal with a related problem, the abuse of the closely held corporation that derives much of its income from sources such as passive investment properties and personal services. Taxpayers have used such companies to avoid the steeply graduated income tax on individuals. For example, an individual in a high tax bracket might organize a corporation (an "incorporated pocketbook") to hold his personal investment portfolio of stocks and bonds, so that the dividends and interest received and retained by the company are taxed at the flat and (for him) relatively low corporate rate. The traditional weapon, the accumulated earnings tax provisions, proved ineffective against such devices, and Congress responded in 1934 with explicit legislation that makes the punitive personal holding company tax dependent upon quite mechanical standards concerning stock ownership and sources of income. ${ }^{59}$ The provisions have since grown in detail. ${ }^{60}$

3. Long-term capital gains shall be taxed at rates substantially lower than those applicable to ordinary income (The capital gains principle)

Capital gains were first given preferential treatment by the Revenue Act of 1921.61 The chief ostensible purpose was to increase tax

58. Id. $\S 534$. The 1921 statute did provide that proof of accumulation of earnings beyond the "reasonable needs" of the business would be "prima facie evidence" of a purpose to evade taxes. Revenue Act of 1921, ch. 136, $\S 220,42$ Stat. 248.

59. Revenue Act of 1934, ch. 277, § 351, 48 Stat. 751. See BitTKer \& Eustice, supra note 3 , at $8-33$ to $8-34$.

60. Compare the provisions of I.R.C. $\$ \$ 541-547$ with Revenue Act of 1934, ch. 277, $\S 351,48$ Stat. 751-52.

61. From 1913 to 1921 , capital gains were subject to the same tax rates as other income; since the latter date they have been accorded preferential tax treatment. The precise conditions of the preferential treatment, and its specific nature, have varied over the years. In the period covering the income years 1922 to 1933, capital gains were 
revenues by counteracting what is now known as the "lock-in effect." Taxing gains accrued over a series of years as a lump sum when realized assertedly retarded the sale of capital assets by greatly enhancing the amount of surtax. ${ }^{62}$ Preferential treatment for capital gains was intended to encourage such transactions and thus to function as an income-averaging device, albeit a crude one. The preference was expected to increase revenues not only by stimulating profit-taking transactions but also by limiting the tax-reducing value of capital losses. ${ }^{63}$ Prevision of undesirable consequences of the principle seems to have been narrowly focused on an alleged unfair boon to "speculators." 64

The proximate consequence of the capital gains principle, which of course has vast ramifications throughout federal income tax law, is that it creates an incentive for taxpayers either to seek capital gains income in preference to ordinary income or to concoct "bailouts"schemes to transform corporate distributions that normally would appear in ordinary income form into proceeds that appear to be capital gains.

Unlike the other principles, the capital gains principle is an independent one, not limited to the corporate context. But because of the binary character of the tax preference it creates-income from an asset sale either qualifies for the treatment or not, with no in-betweens-it became crucial for the law to characterize corporate distributions and

separated and accorded a preferential maximum rate. The system inaugurated by the Revenue Act of 1934 and effective until 1938 required that percentages of capital gains be included in income; the specified percentages varied with the length of time the assets had been held. In the next period, beginning with the Revenue Act of 1938 and essentially continuing into the present, features of the preceding periods were combinedpercentage inclusion of capital gains and losses (but not on a sliding scale) and an alternative flat rate tax. E. Griswold \& M. Graetz, Federal Income Taxation: Principles AND Policies 629-31 (1976); Wells, Legislative History of Capital Gains under the Federal Income Tax, 1913-1948, 2 NAT'L TAX J. 12 (1949). The present provisions are codified at I.R.C. $\$ \S 1201-1254$.

The wavering legislative treatment, as well as the confusion in the case law, may reflect deep uncertainty about the justification, if any, of preferential treatment for capital gains. See M. Chirelstein, Federal Income Taxation $₫ 16.01$ (1977). See generally L. Seltzer, The Nature and Tax Treatment of Capital Gains and Losses (1951); Blum, $A$ Handy Summary of the Capital Gains Arguments, 35 Taxes $247(195 \rightarrow$ Miller, The "Capital Asset" Concept: A Critique of Capital Gains Taxation (parts I-II), 59 YALE L.J. $837,1057(195 \rightarrow$ Surrey, Definitional Problems in Capital Gains Taxation, 69 Hakv. L. REv. 985 (1956).

62. See H.R. REP. No. 350, 67th Cong., 1st Sess. 10-11 (1921), reprinted in J. SEIDMAN, supra note 20 , at $813-15$ (1938). These comments relate directly to a 1920 House bill provision that was not enacted; they were, however, part of the process leading to the 1921 act.

63. See id.

64. See the comments of Senators Walsh and Lenroot, quoled in J. SEIDMAN, supra note 20 , at 815 . 
shareholder dispositions of corporate stock. Thus the third decision is essential background for appreciating the fourth and fifth.

4. Corporate distributions to shareholders are presumptively to be treated not as capital gains but as ordinary income, that is, as dividends (The dividend principle)

One aspect of the dividend principle-that dividends are to be taxed at ordinary rates-is the result not of decision but of inaction. In 1921, when giving preferential tax treatment to capital gains, Congress failed to specify preferential treatment for dividends. The inaction was perfectly consistent, of course, with the rationale of counteracting the lock-in problem, for the problem does not extend to dividend payments. Corporations can generally avoid sporadic, lump-sum dividends to shareholders by retaining current earnings or dipping into accumulated earnings as necessary to establish a consistent dividend payout pattern. Shareholders are free to make their preferences known by investing in or avoiding companies with regular payout patterns.

A subtler aspect of the dividend principle-that corporate distributions are "presumptively" dividends-appears in the tracing rule that corporate distributions are deemed to come first out of corporate earnings and profits to the extent thereof, a rule that appeared in the course of Congress's statutory elaboration of the idea that dividends are "out of earnings and profits." ${ }^{5}$ Obviously, the rule is designed to eliminate taxpayer discretion in naming the source of a given distribution-a power that might be used to evade taxes on virtually all distributions.

In conjunction with some of the other basic principles, the dividend principle has prompted much taxpayer maneuvering and governmental reaction. As noted in the preceding discussion of the distribution principle, ${ }^{66}$ one comparatively simple maneuver is merely to disguise dividends as something else. Especially in close corporations, what are in substance distributions of corporate profits to shareholders as such have been cast, often successfully, in the form of nontaxable loans, singly taxed salaries, interest payments on loans, payments for or sales of property and services, and the like. To be sure, there would be pressure to disguise dividends even if undisguised dividends were taxed at capital gains rates, ${ }^{67}$ but the pressure would not be as intense. One

65. See note 36 supra.

66. See pp. 100-04 supra.

67. See pp. 147-49 infra (tracing effects of taxing dividends at capital gains rates). 
should think of the actual development of disguised dividend techniques as a result of the double-tax system (the separate tax and distribution principles operating together), significantly aided and abetted by the dividend principle.

In any event, a considerable body of case law attempts, rather inconclusively, to deal with these behaviors: there are efforts to find "excessive" salaries and to recharacterize the excess as a dividend payment; ${ }^{68}$ to find shareholder loans to be equity investments in substance; ${ }^{69}$ to find sales between corporations and their shareholders "unfair" to the corporation and to that extent a withdrawal of profits rather than a bargained exchange; ${ }^{70}$ and so forth. ${ }^{71}$ In particular, the problems of distinguishing true debt (and its attendant, singly taxed interest payments) from disguised equity (with its doubly taxed dividend payments) have proven so intractable, and therefore have generated such a substantial volume of activity within the culture, ${ }^{72}$ that one might characterize the policy decision to treat corporate payments to debtholders differently from corporate payments to shareholders as a distinct one almost equal in magnitude to the others listed here. ${ }^{73}$

More complicated disguises of dividends emerged in the culture as shareholders devised techniques combining simple strategies with the next three basic principles.

5. Shareholder dispositions of stock are presumptively to be treated purely as dispositions of capital assets, that is, independently of corporate-level events (The corporate veil principle)

The corporate veil principle might be labelled blandly the disposition principle, but here is named after a more interesting feature. The principle has several aspects. The first is that stock is a capital asset: gain from its sale or exchange may qualify for preferential tax treatment. No one seems ever to have doubted that stock is a proto-typical capital asset. The Revenue Act of 1921 did not explicitly include corporate stock in its definition of "capital asset," but did define the

68. See, e.g., Annot., [1977] I Stand. Fed. Tax Rep. (CCH) If 1370-1376 (1976).

69. See, e.g., Annot., [1977] 3 Stand. Fed. Tax Rep. (CCH) ף 2377.654-.73 (1976).

70. See, e.g., Annot., in id. at I 2377.48-.489 (1976).

71. See generally Annot., in id. at 9 2377.0248-2377.90 (1976); Comment, Disguised Dividends: A Comprehensive Survey, 3 U.C.L.A. L. Rev. 207 (1956).

72. See Bittker \& Eustice, supra note 3, at 4-1 to 4-59; id. (Supp. 1977, no. 2) at S4-1 to $\mathrm{S} 4-18$ (citing sources).

73. The decision is clearly treated as a major policy problem $\rightarrow$ Warren, The Corporate Interest Deduction: A Policy Evaluation, 83 YALE L.J. 1585 (1974), and Note, Toward New Modes of Tax Decisionmaking-The Debt-Equily Imbroglio and Dislocations in Tax Lawmaking Responsibility, 83 HARv. L. Rev. 1695 (1970). 
term as property held for investment rather than consumption, ${ }^{74}$ a criterion that catches stock if anything. This too was consistent with the aim of counteracting the lock-in effect, for only property that its owner would normally want to sell at some point (investment property but not property held for consumption) could be subject to the cloud of a potential lump-sum tax on realized gain. And appreciation in the value of stock is often thought to be an easily locked-in gain. A second aspect of the principle is indicated by the word "presumptively." Bailout techniques have prompted Congress to treat stock as something other than a capital asset under certain circumstances, which will be touched upon below. ${ }^{75}$

A more subtle but important aspect of the fifth principle, also implicit in the 1921 decision, is that stock dispositions are generally treated without regard to corporate-level events and attributes. Thus, all gain from the sale of a share of stock is routinely treated as capital gain. Basically, the law divides sales proceeds into only two parts: proceeds are first considered nontaxable recoveries of the selling shareholder's investment to the extent of his "basis" or historical cost; all excess proceeds are capital gains. This is true even though such gains may be attributable, not just to appreciation in the value of the underlying corporate assets, but in whole or part to the corporation's accumulated earnings. But this existing method of conceptualizing proceeds from sales of stock is not written in the stars. A threefold division of proceeds is rationally conceivable and is in fact used for corporate distributions. Under this long-familiar pattern, ${ }^{76}$ distributions are deemed to come first out of the corporation's earnings and profits to the extent thereof, that is, to be dividends taxable at ordinary rates. Excess amounts are then treated as recoveries of the shareholder's investment to the extent of his basis in the stock. Any further excess amounts-due, one supposes, to unrealized appreciation in the value of distributed assets-are treated as capital gains. One might wonder why this pattern was not adopted for stock sales as well.

The answer may be grasped by imagining a system in which the corporate veil decision had not been made. Suppose that a corpora-

74. The term "capital asset" was defined to mean "property acquired and held by the taxpayer for profit or investment for more than two years (whether or not connected with his trade or business), but did not include property held for . . personal use or consumption . . . or inventory. . ." Revenue Act of 1921, ch. 136, $\S 206(a)(6), 42$ Stat. 243 (emphasis added). Curiously, the present provision, I.R.C. $\$ 1221$, omits the "for ... investment ... not ... consumption" language and is thus less clear in its implied inclusion of corporate stock.

75. See pp. 119-20 infra.

76. See I.R.C. $\$ 301$. 
tion's "earnings and profits" 77 were regularly allocated to separate corporate accounts for each outstanding share of stock. Suppose further that the law had made the first four decisions but had not adopted the corporate veil aspect of the fifth principle. Under such a system, any corporate distribution with respect to a share of stock would be deemed to come first out of the share's earnings and profits account. It would constitute, to that extent, taxable ordinary income to the shareholder and would reduce that particular share's earnings and profits account by the same amount. ${ }^{78}$ Proceeds from the sale of a share of stock to an unrelated third party would, to the same extent, constitute ordinary income to the selling shareholder, and the earnings and profits account would be reduced accordingly. ${ }^{79}$ Whenever sales proceeds equaled or exceeded the share's earnings and profits account, the latter would obviously be reduced to zero. Clearly, if this system were working properly, the tax treatment of stock-sale proceeds would be the same as that of corporate distributions.

The problem lies in successfully implementing such a hypothetical system. The corporation would be compelled to identify and keep a separate earnings and profits account for each share of stock. Moreover, every sale of stock would require two legally mandated exchanges of information. The selling shareholder would be obliged to get, or the corporation to give, information about the preexisting status of the earnings and profits account of each share involved. And the corporation would be obliged to get, or the selling or buying shareholder to give, information about the terms of the stock sale. With traditional information-processing technology, such a system would be incompatible with a cheap, smoothly functioning capital market for shares of stock in large, publicly held corporations. And even in a world with advanced, computerized bookkeeping, more fundamental

77. "Earnings and profits" is the Code's jargon for a firm's current and retained earnings, as adjusted in numerous ways for tax purposes. See Andrews, supra note 37, at 1404-13; Katcher, What is Meant by Earnings and Profits, in Proceedings of The New York University Eighteenth Annual Institute of Federal Taxation 235 (H. Sellin ed. 1960).

78. Suppose $X$ Corporation, formed a few years ago, has outstanding 100 shares of common stock and no other equity securities. No stock has been sold by shareholders since formation of the company. Its accumulated profits are $\$ 500$; thus, $\$ 5$ has been allocated to each share's earnings and profits account. $X$ then distributes to the shareholders $\$ 20$ per share. Five dollars of each $\$ 20$ payment would be a dividend taxable as ordinary income. All earnings and profits accounts would be reduced to zero.

79. If a shareholder of the corporation described in the preceding footnote sells one share of stock for $\$ 20$ before the corporate distribution, $\$ 5$ of his proceeds would be taxed as ordinary income. The earnings and profits account for that share would be reduced to zero and, upon the ensuing distribution, the buyer, unlike the other shareholders, would include none of the $\$ 20$ in ordinary income. He would not suffer, as under current law, from the "miracle" of income without gain. 
problems would endure, for with different classes of stock, significant ambiguities and complexities would inhere in allocating earnings and profits to individual shares. ${ }^{80}$ It is readily understandable that the law did not opt for the hypothetical regime. The desire for efficient capital markets and the administrative nightmares of the alternative system have virtually forced the adoption of the veil principle.

Notice, however, the consequences of the decision. In effect, the law has conceded that at least one form of bailout, the stock sale to unrelated third parties, is unquestionably legitimate. As a corollary, the buyer who receives a dividend immediately after buying stock at a fair price has taxable income even though, from his point of view, his investment has not yet increased in value-the "miracle of income without gain."

This aspect of the corporate veil principle has interacted with the distribution and capital gains principles to produce two important cultural consequences. One is the widespread use of the retained earnings strategy to avoid the double tax. Corporate earnings are plowed back into the business, and shareholders later reap the gains by selling some or all of their stock at prices that reflect the corporation's retained earnings. This strategy subjects corporate earnings not to a corporate-level ordinary income tax plus an immediate shareholderlevel ordinary income tax on dividends, but rather to a corporate-level ordinary income tax plus a deferred shareholder-level capital gains $\operatorname{tax}^{81}$

The second and more interesting consequence is that the stock-sale bailout has been perceived as so unavoidable and thus as so "natural"

80. If a company has noncumulative preferred stock, for example, allocating accumulated earnings among preferred and common shares would be arbitrary, since the preferred's actual share would depend upon future decisions of the directors.

81. If the shareholder in note 43 supra operates in corporate form but retains earnings and later turns into cash the value of the after-corporate-tax retained earnings (\$52) by selling some of his stock and claiming long-term capital gains treatment, the total tax burden will be $\$ 61$-the corporate tax of $\$ 48$ plus the capital gains tax of .25 (\$52), or $\$ 13$. Part of it (\$13) will be deferred. This tax pattern may be called the "corporate undertax" model. The corporate overtax model would impose a total tax burden of $\$ 84.40$, the proprietorship model one of \$70. See notes $43 \& 45$ supra.

These examples may create a misleading impression of the potential for tax reduction inherent in the retained earnings strategy. If, for example, the shareholder in the preceding paragraph had already incurred substantial net long-term capital gains of over $\$ 50,000$, then his marginal rate for capital gains would be $35_{\%}^{\circ}$ (one half of $70 \%$ ). See I.R.C. $\$ 1201(b)$, (c). If he cashed in his capital gain by selling stock, the corporate undertax model would produce a total tax burden of $\$ 48+.35(\$ 52)$, or $\$ 66.20$. This is still less than the tax incurred under the proprietorship model, but the difference is smaller. Moreover, for shareholders with marginal tax rates of $48 \%$ or less, the corporate form is generally disadvantageous. For those in the $48 \%-70 \%$ range, there is less likely to be an advantage as one moves downward from $70 \%$, unless the value of the deferral of the capital gains portion of the total tax becomes correspondingly greater. 
that the stock sale has become the paradigm of a legitimate bailout. Some of its attendant characteristics have been transmuted into criteria of permissible bailouts in other contexts. Specifically, since a sale of common stock typically involves a sacrifice of proportionate voting power and equity interest in the corporation's residual earnings, the law has required that this sacrifice be made in order to legitimate certain other types of bailouts. ${ }^{82}$ This crucially important tendency is in one sense very odd: there seems to be no intrinsic, rational connection between sacrifice of equity interest and voting control and the treatment of income as capital gain. ${ }^{83}$

The corporate tax culture becomes really interesting-for the tax lawyer-when transactions jointly invoke the dividend principle and the capital gains and corporate veil principles. With these principles established, the law early confronted the problem of dealing with liquidations and redemptions, hybrid transactions that involve both a corporate distribution and a disposition of stock. The distributive aspect, the flow of assets from corporation to shareholder, points to tax treatment at ordinary rates; the dispositional aspect, the shareholder's relinquishing shares of stock, points to tax treatment at capital gains rates. The legal response to the dilemma has been to bottom the tax treatment upon the relative magnitude of the dispositional aspect of the transaction. Complete liquidations have thus been analogized to stock sales since $1924 .^{84}$ Treatment of hybrid transactions, such as partial liquidations or redemptions, that affect only part of a corporation's stock is intrinsically more difficult to specify. The result has been a constant stream of regulatory pronouncements, statutory elaborations, and fighting in the courts. ${ }^{85}$

The main provision governing redemptions ${ }^{86}$ reflects these tensions. Its predecessor in the Revenue Act of 1921 was fairly simple in language. The key and perduring phrase "essentially equivalent to a dividend" marked out redemptions not qualifying for capital gains treatment. ${ }^{87}$ The need to tax some redemptions as dividend distribu-

82. See pp. 112-14 infra.

83. See generally Blum, A Handy Summary of the Capital Gains Arguments, 35 TAXES $247(195 \rightarrow$ Surrey, Definitional Problems in Capital Gains Taxation, 69 Harv. L. Rev. 985 (1956).

84. Revenue Act of 1924, ch. 234, § 201(c), 43 Stat. 255; S. ReP. No. 398, 68th Cong., lst Sess., reprinted in 1939-1 (Part 2) C.B. 266, 274.

85. See Bittker \& Eustice, supra note 3, at 9-1 to 9-68; id. (Supp. 1977, no. 2) at S9-1 to S9-22; SURREY \& WARREN, supra note 3, at 396-438, 448-62.

86. I.R.C. $\S 302$.

87. The provision reads as follows:

A stock dividend shall not be subject to tax but if after the distribution of any such dividend the corporation proceeds to cancel or redeem its stock at such time and in 
tions was then seen rather narrowly as a corollary of the exemption of stock dividends from inclusion in shareholder income; 88 the Revenue Act of 1928, however, generalized the "essential equivalence" test by making it applicable to all redemptions, not just to redemptions of stock issued as a dividend. ${ }^{89}$

The open-ended character of the test obviously left room for much argument and litigation between the Service and taxpayers. In 1954, in response to " 'the morass created by the [judicial] decisions' " and " 'the considerable confusion' " in the area, Congress added the present Code's mechanical "safe harbor" tests. ${ }^{90}$ Basically, these provisions require the sacrifice of a specified quantum of a shareholder's proportionate equity and voting interests before a redemption of his stock will be deemed a disposition of shares that qualifies for capital gains treatment. A simple set of rules focusing merely on reductions in the separate interests of individual shareholders, however, is easy to circumvent; hence Congress has struggled to formulate attribution rules, which have their own complex lore.91 And because a corporate distribution can easily be disguised as a "sale" of stock to a specious outsider such as a corporation actually owned and controlled by the "selling" shareholder, the Code has been forced to add further provisions to define and deal with "redemption through use of related corporations." 92

Similarly discriminating treatment applies to partial liquidations. Some qualify for capital gains treatment, but some do not. ${ }^{93}$ Here the law built on the decision that complete liquidations partake more of dispositions than of distributions. Shareholders relinquishing stock in a putative partial liquidation qualify for capital gains treatment if

such manner as to make the distribution and cancellation or redemption essentially equivalent to the distribution of a taxable dividend, the amount received in redemption or cancellation of the stock shall be treated as a taxable dividend to the extent of the [post Feb. 28, 1913] earnings or profits . . . .

Revenue Act of 1921, ch. 136, § 201(d), 42 Stat. 228-29.

88. The provision was enacted in response to Eisner v. Macomber, 252 U.S. 189 (1920). See United States v. Davis, 397 U.S. 301, 308 (1970) (discussion of legislative history).

89. Revenue Act of 1928, ch. 852, $\S 115(\mathrm{~g})$, 45 Stat. 822.

90. I.R.C. $\S \S 302(b)(2)$, (3). See United States v. Davis, 397 U.S. 301, 309-10 (1970) (citing Ballenger v. United States, 301 F.2d 192, 196 (4th Cir. 1962); and H.R. REP. No. 1337, 83d Cong., 2d Sess. 35, reprinted in [1954] U.S. Code Cong. \& AD. News 4025, 4060) (discussion of legislative history).

91. See I.R.C. $\S 3 \rightarrow$ Ringel, Surrey \& Warren, Attribution of Stock Ownership in the Internal Revenue Code, 72 Harv. L. Rev. 209 (1958) (calling for more uniformity and simplification). Though complex as formulas, these rules often are fairly easy to apply. This does not mean, however, that they are free of ambiguity. See [1977] 3 STAND. FED. TAX REP. (CCH) IT 2389-2394.05 (1976) (regulations and annotations).

92. I.R.C. $\$ 304$.

93. Id. $\S 346$. 
their exchange of stock for corporate assets is one of a series of redemptions leading to complete liquidation of the corporation, or if the exchange results from the liquidation of one of two or more separate businesses carried on by the corporation. ${ }^{94}$ Significantly, the law thus involves the taxpayers, the Service, and the courts in the exercise of trying to perceive two or more "business enterprises" operating within the single legal entity, the corporation, in order to determine whether the cessation of one of the enterprises-a complete liquidation of one business, though not of the legal entity-is what led to the distribution in question. Inevitably, this attempt to accomodate business realities in addition to corporate legal forms has created a hothouse for the growth of litigation. ${ }^{95}$

The corporate veil, capital gains, and dividend principles have thus been compromised to make the stock-dispositional aspect of liquidations and of some redemptions and partial liquidations determinative of tax treatment. The resulting liquidation and redemption bailouts constitute a first category of problematic bailouts, here called "simple" bailouts because they do not involve the sixth or seventh principles. ${ }^{96}$ The legal treatment of these bailouts is highly unstable, inherently so because of the tensions among the third, fourth, and fifth principles. Even the simple bailouts that are currently legal, such as straightforward complete liquidations, are not really endowed with the same legitimacy as the sale of stock to unrelated third parties. Leading commentators, for example, have expressed skepticism about the validity of analogizing liquidations to stock sales. ${ }^{97}$ And, of course, the Service continually challenges many redemptions and partial liquidations as impermissible bailouts. ${ }^{98}$

A related distribution-disposition hybrid has produced a higherorder simple bailout, the bootstrap acquisition-a sale of stock at arm's length to a third party combined with a financing distribution to either seller or buyer. The bootstrap acquisition is useful, for example, when a controlling shareholder wants to sell his entire interest in the corporation, but the potential buyer can afford to purchase only part of the stock at a price reflecting the true value of the underlying corporate assets. To accommodate both interests, the corporation is

94. Id. $\S 346(\mathrm{~b})(1),(2)$.

95. See generally Caplan, The Five-Year Active Business Rule in Separations and Partial Liquidations, 1961 S. CAL. TAX Inst. 211; McGaffey \& Garmer, Factors That Will Today Prove a Distribution Was Made in Partial Liquidation, 31 J. TAx. 204 (1969).

96. See pp. 117-35 infra.

97. BitTKER \& Eustice, supra note 3, at 11-3.

98. See generally Annot., [1977] 3 Stand. Fed. Tax Rep. (CCH) IT 2310.025-2314.79, 2496.1933-2496.45 (1976) (annotations to I.R.C. $\S \S 302,346$ ). 
"thinned down" to the buyer's scale. The seller, before the sale of all his stock, may cause the corporation to pay him a sufficiently large dividend to compensate for a lower selling price; or, either before or after the sale of part of his stock, he may have a sufficiently large portion of his stock redeemed to make purchase of the remainder feasible for the buyer. Alternatively, the buyer, before his stock purchase, may borrow what he needs to pay the full price of all the seller's stock and then, after the purchase, thin down the corporation by a dividend to himself or a redemption of part of his shares, in order to repay the loan.

Viewed in isolation, the stock-sale component of any of these variations is clearly a disposition invoking the corporate veil decision and qualifying for capital gains treatment. But the tax treatment of the financing component, or thinning down process, may seem, when viewed as an isolated step, to depend on the form and timing of the particular financing device. If the distribution is not cast in the form of a redemption, that is, if the recipient does not at the moment of distribution give up shares of stock, the dividend principle would seem to require ordinary income tax treatment. If, however, the distribution takes the form of a redemption, timing may seem crucial. If the seller has some shares redeemed before selling the remainder, the redemption may very well appear dividend-equivalent under the Code's compromise between the dividend and corporate veil principles, ${ }^{99}$ because the seller may not have sacrificed a sufficiently large portion of his equity rights and voting power to satisfy the statutory tests for capital gains treatment. Conversely, if he first sells a portion of stock and then has the corporation redeem the remaining shares, the redemption will appear to meet these tests quite easily, since immediately afterwards the seller has no interest in the corporation at all. Similar problems of timing could affect the buyer. ${ }^{100}$

99. I.R.C. § 302. See p. 112 supra.

100. The issues raised in the text may better be understood by considering five variations of a simple numerical example. The first three variations deal with the timing issue, the next two with the form-of-distribution issue. Assume that $X$ Corporation has a fair market value of $\$ 200$ and earnings and profits of $\$ 100$. The sole shareholder $(S)$ wants to sell all his stock. The potential buyer $(B)$ can pay only $\$ 100$.

(1) $X$ redeems $50 \%$ of $S$ 's stock for. $\$ 100$. Afterwards, $S$ sells $B$ the other $50 \%$, also for $\$ 100$. The redemption, however, might be considered dividend-equivalent, since $S$ still holds $100 \%$ of the outstanding shares immediately after it occurs; he has not yet made the required sacrifice of proportionate ownership and voting power. See I.R.C. $\S 302$ (b)(1), (2), (3).

(2) $B$ temporarily borrows $\$ 100$, pays $S \$ 200$ for all of the $X$ stock, and then causes $X$ to redeem $50 \%$ of the shares for $\$ 100$. $B$ uses the $\$ 100$ redemption payment to repay the loan. But this merely puts $B$ in the position of $S$ in the preceding example: after the 
The case law offspring of the bootstrap acquisition disclose many other factual variations that seemingly bear on tax results. ${ }^{101}$ The basic question is whether variations in form and timing should affect the overall tax results, or whether a uniform tax treatment should be applied to all bootstrap acquisitions that are functionally equivalent in their business results. The latter option entails a further choice among possible tax patterns. The courts have yet to achieve complete

redemption, $B$ has the same proportionate ownership interest and voting power that he had immediately before it, so the redemption might be considered dividend-equivalent.

(3) $S$ sells $50 \%$ of his $X$ shares to $B$ for $\$ 100$, then causes $X$ to redeem his remaining shares for $\$ 100$. Immediately after the redemption, $S$ has no interest in $X$, and thus appears to qualify for "exchange" treatment-that is, for taxation at capital gains rates.

(4) $X$ makes a $\$ 100$ distribution before the stock sale. $S$ does not surrender any stock. $S$ then sells all his shares to $B$ for $\$ 100$. Here, the distribution appears to be a straightforward dividend taxable at ordinary rates, even though the whole transaction is economically equivalent to those described in the first three situations.

(5) $B$ borrows $\$ 100$ and buys all of $S$ 's stock for $\$ 200$. X Corporation then distributes $\$ 100$ to $B$, who does not surrender any stock. $B$ repays the loan. Again, the distribution seems a straightforward dividend, but why the tax result should depend upon the formality of surrendering stock certificates (thus creating the appearance of a redemption) is unclear.

101. The basic patterns set out in note 100 supra are frequently complicated. The deal might be financed out of post-acquisition earnings of the purchased company. See, e.g., Ray Edenfield, 19 T.C. 13 (1952) (type (3) situation, but redemption accomplished with notes; payments on notes not considered dividends to buyer, i.e., not likened to type (2) situation or type (5) situation). There might be a bootstrapped shifting of control to an existing shareholder. See, e.g., Holsey v. Commissioner, 258 F.2d 865 (3d Cir. 1958) (one $50 \%$ shareholder redeemed in full, leaving the other a $100 \%$ owner; redemption not considered dividend-equivalent). In the latter case, the transaction might have been recharacterized as a sale by one shareholder to the other, followed by a redemption from the latter (as in a type (2) situation); or as a dividend to both shareholders, followed by one's purchase of the other's shares (as in a type (4) situation). Both treatments, while not the same, would have been harsher than the actual result.

Another variation occurs when the distribution to the selling stockholder in effect discharges the buyer's previously contracted obligation to purchase all of the seller's stock. In this situation, the distribution may be recharacterized as a dividend to the buyer, followed by his use of the money to buy stock from the seller. See Wall v. United States, 164 F.2d 462 (4th Cir. 1947). In general, however, the cases and rulings have been favorable to taxpayers. See, e.g., Milton F. \& Robbie Priester, 38 T.C. 316 (1962) (obligor assigned contract to third party, who then purchased the stock; held, no dividend to obligor); Rev. Rul. 69-608, 1969-2 C.B. 42 (continuing shareholder can avoid dividend treatment so long as there is no existing primary and unconditional obligation on his part to purchase shares later redeemed).

Casner v. Commissioner, 450 F.2d 379 (5th Cir. 1971), involved a variant of the type (4) situation. The corporation was thinned down by a pro rata distribution to all shareholders, whereupon some of them bought out the others. But the court in essence recharacterized the transaction as a type (2) situation, yielding an even harsher tax result: the buying shareholders were treated as getting direct dividends and constructive dividends (those paid directly to the sellers), which were used to meet the "real" purchase price obligation. The decision is a bad one, not because the taxpayers suffered, but because a court entering the recharacterization game ought to set out all the functionally equivalent alternative routes to a certain business result-in this context, all five of the situations set out in note 100 supra-and give some reasons for choosing one as the paradigm. When each court focuses upon only two functionaly equivalent alternatives at a time, chaos in the decisional law is the most likely result. 
rationalization of the area, but through a fascinating development of case law, starting with the leading case of Zenz $v$. Quinlivan, ${ }^{102}$ the treatment of many of the variations on the bootstrap theme seemingly has been settled for the short run, often to the detriment of the dividend principle. ${ }^{103}$

It should be stressed that the tension and confusions in the redemption, partial liquidation, and bootstrap acquisition areas are very likely irresolvable. Impossibility theorems in economics provide a tempting analogy. ${ }^{104}$ Given the dividend and the corporate veil principles, spurred on by the capital gains incentive, the treatment of hybrid transactions necessitates a choice among competing principles. Whereever the line is drawn, taxpayers will try to fudge it in one direction, and the Service will try to fudge it in the other. And fudging tends to engender statutory complexity. Whether a stable level of statutory complexity has now been reached or will soon be achieved or even whether an equilibrium exists at all is a difficult and perhaps unanswerable question. It appears, however, that radical simplification is not likely except as a result of bold strokes-reversal of one or more of the basic decisions-and in any event is more likely to be temporary than permanent. One can only hope that the new levels of com-

102. 213 F.2d 914 (6th Cir. 1954) (contemporaneous sale and redemption characterized as type (3) pattern in note 100 supra; redemption not considered dividend to selling shareholders).

103. See, e.g., United States v. Carey, 289 F.2d 531 (8th Cir. 1961) (redemption preceded sale but was part of prearranged transaction; redemption not considered dividend). Although the Carey case indicates that a type (l) situation may be treated favorably in the manner of a type (3) situation, other cases, following Wall v. United States, 164 F.2d 462 (4th Cir. 1947), indicate that a type (2) situation will not be so treated. See Television Industries, Inc. v. Commissioner, 284 F.2d 322 (2d Cir. 1960) (buyer borrowed funds, purchased all shares, and had some redeemed to repay loan; redemption held to constitute dividend). And in Casner v. Commissioner, 450 F.2d 379 (5th Cir. 1971), discussed in note 101 supra, the court assimilated what was basically a type (4) transaction into the type (2) pattern. But fortunately for well-advised taxpayers, the threatening implications of Casner were blunted and the basic validity of the Zenz pattern confirmed in Enoch v. Commissioner, 57 T.C. 781 (1972).

See gener $\rightarrow$ Jassy, The Tax Treatment of Bootstrap Stock Acquisitions: The Redemption Route vs. the Dividend Route, 87 HARv. L. REv. 1459 (1974) (arguing for elimination of differences in tax result that depend on which financing route is chose $\rightarrow$ Kingson, The Deep Structure of Taxation: Dividend Distributions, 85 YALE L.J. 861, 884 (1976). See a $\rightarrow$ Ginsburg, Letter to the Editors, 86 YALE L.J. 798, 801-05 (1977), a $\rightarrow$ Kingson, Author's Reply, id. at 806, 808 (debate about analysis of bootstrap cases in Kingson's article).

104. The impossibility theorem in social welfare economics demonstrates that, if one accepts certain ascertainable and inconsistent conditions of "fairness" in social choice, one cannot maximize social welfare through collective choice, i.e., by aggregating individual preferences into a single societal preference. The theorem was first formulated by Kenneth Arrow. See K. Arrow, Social Choice and Individual Values (1951). For discussion and explanation of Arrow's "paradox," see R. LUCE \& H. RAIFfa, Games AND DeCISIONS 327, 333-45, 368-70 (1957). 
plexity eventually reached after a new rule has been in operation will be lower than those prevailing under the old.

6. Formal changes in corporate-shareholder relationships that nevertheless involve a substantial continuity of ownership in a business enterprise shall not be recognized for tax purposes (The nonrecognition principle)

Since the time of the capital gains decision, reorganizations (both amalgamating and divisive) and incorporating transactions have been given nonrecognition treatment. The theory is that the shareholders involved, though perhaps realizing gain in a strict constitutional sense, do not actually realize the value of their investments, because they do not dispose of them but continue them in new and substantially similar forms. ${ }^{105}$ In essence, these nonrecognition rules embody the general notion of income tax law that accrued gain must be realized before it will be taxed. ${ }^{106}$ Though certain nonrecognition rules arise from particular policy decisions, ${ }^{107}$ they principally reflect a desire to acknowledge for tax purposes a substantial continuity of ownership interest. Conceivably, the realization requirement itself, and a fortiori many of the Code's particular nonrecognition rules, could be abolished. But Congress long ago eschewed a simple, extremist position in favor of discriminating in many individual contexts between formal legal changes in property interests that do, and those that do not, involve a sufficient discontinuity to trigger recognition of income for tax purposes.

The decision to define nonrecognition transactions induced two sets of consequences in the corporate tax culture. The first consists of all the cultural products and activities centered around the basic task of giving operational content to the nonrecognition decision. Exactly which criteria should distinguish the "sale" of a business from a "merger"? Exactly which test will give specific content in specific contexts to the underlying concept of continuity of interest which is at the heart of all nonrecognition transactions? The task is truly

105. Revenue Act of 1918, ch. 18, $\S 202(\mathrm{~b}), 40$ Stat. 1060 (reorganizations, mergers, consolidations); Revenue Act of 1921, ch. 136, $\S 202(c), 42$ Stat. 230 (transfers to controlled corporations and "reorganizations" as partially defined). Before the introduction of I.R.C. $\$ 355$ in 1954, however, divisive transactions had to meet the "reorganization" definition to bring any nonrecognition provision into play. See Revenue Act of 1928, ch. 852 , $\$ 112(\mathrm{i})(\mathbf{1})(\mathrm{B}), 45$ Stat. 818. The present statutory provisions are I.R.C. $\$ \S 351-383$.

106. The classic discussion of the realization requirement is the debate between Justice Pitney and Justice Brandeis in Eisner v. Macomber, 252 U.S. 189 (1920).

107. E.g., I.R.C. $\$ 1033$ (nonrecognition of gain on involuntary conversions). 
enormous, given the multiplicity of ways in which businesses can operate and the manifold objectives they may serve. ${ }^{108}$

The second set of consequences is of greater conceptual interest. The nonrecognition provisions, principally in conjunction with the corporate veil decision, have spawned a second class of problematic bailouts, the "nonrecognition bailouts." Remarkably, the evolution of the law with respect to these bailouts displays aesthetically pleasing attributes of completeness and symmetry. By attending in turn to each of the major nonrecognition provisions, one can anticipate the corresponding bailout, and it is with a sense of novelty within a fundamentally familiar rhythm that one learns in each situation of the progression of case law development and statutory response. Here, the progression of cultural evolution into cumulative doctrinal complexity appears at its most dramatic.

\section{a. Stock Dividends and the Preferred Stock Bailout}

In the celebrated case of Eisner $v$. Macomber, ${ }^{109}$ the Supreme Court decided that a dividend of common stock on already outstanding common stock was not "income" within the meaning of the Sixteenth Amendment. Justice Pitney, writing for the Court, reasoned that income means gain "derived" from labor or capital and that the stockholder's gain in the case before him was not really severed or separated (that is, derived) from the original investment; rather, the stockholder simply continued the investment, which was now evidenced by new pieces of paper. ${ }^{110}$ This apparently picayune focus on the term "derived" implies that income taxable to shareholders ordinarily must reflect major substantive and major formal changes in their interests, that is, both increase in net worth (wealth) and a significant change in form.

Subsequent cases revealed that not all stock dividends were automatically excluded from income, ${ }^{111}$ but the basic holding of Macomber was not overruled. Hence taxpayers began to exploit the notion that receipt of a stock dividend was not recognized for income tax purposes, and Congress responded with a fairly detailed Code provision

108. What is involved in trying to operationalize the nonrecognition provisions may be grasped by studying Chapters 13,14, and 16 of BitTker \& Eustice, supra note 3, at 13-1 to 14-152, 16-1 to 16-70; id. (Supp. 1977, no. 2) at S13-1 to S14-46, S16-1 to S16-22; interspersed throughout these materials, however, are discussions of issues that fall under the second set of consequences identified in the text.

109. 252 U.S. 189 (1920).

110. Id. at 207-11.

111. See SURREY \& WARREN, supra note 3, at 303-07. 
describing those stock dividends that do and those that do not trigger a shareholder-level tax. ${ }^{112}$ Tiresomely long regulations govern its application. ${ }^{113}$

The "preferred stock bailout" is one of the more interesting schemes that taxpayers devised to take advantage of Macomber. Its purpose is to enable common stockholders to extract corporate profits at capital gains rates without sacrificing any of their proportionate equity interests or voting power. A classic version, illustrated by Chamberlin $v$. Commissioner, ${ }^{114}$ involves three steps. First, the corporation declares a preferred stock dividend on its common shares. Taxpayers, relying on Macomber's nonrecognition principle, treat it as a nontaxable stock dividend. Next, after satisfying the holding period requirement for long-term capital gains treatment, ${ }^{115}$ they sell the preferred stock to an outside investor seeking a steady return, often to a financial intermediary such as an insurance company. ${ }^{116}$ Relying on the corporate veil decision, they report their gain as capital gain. Finally, after the insurance company has received dividend income for a prearranged number of years, the corporation redeems the preferred stock at approximately the same price the insurance company paid; this produces

112. I.R.C. § 305. The Tax Reform Act of 1969, Pub. L. No. 91-172, § 421, 83 Stat. 614 (amending I.R.C. $\S 305$ ), responded to various abuses involving stock dividends by effecting major changes in the 1954 Code. See S. REP. No. 91-552, 91st Cong., lst Sess. 150-53 (1969) (tracing history of tax avoidance schemes and Treasury and congressional responses). A major target of the 1969 changes was the practice whereby some publicly held corporations made periodic redemption offers to shareholders in lieu of dividends. These plans were tantamount to giving shareholders the option to take a cash distribution (by accepting the offer and surrendering some shares for redemption) or to increase their proportionate interests in the business (by refusing the offer). This was functionally equivalent to an option to take either a cash dividend or a stock dividend. Id. at 151 . See genera $\rightarrow$ Chirelstein, Optional Redemptions and Optional Dividends: Taxing the Repurchase of Common Shares, 78 YALE L.J. 739 (1969). Since the latter option was taxable, the 1969 changes made it possible to tax the periodic redemption scheme as well. I.R.C. $§ 305(\mathrm{c})$; Treas. Reg. $\S 1.305-3(\mathrm{e})$, Example (9) (1973, as amended 1974).

113. Treas. Reg. $\S \S 1.305-1$ to $1.305-2$ (1973), $1.305-3$ (1973, as amended 1974), $1.305-4$ (1973), 1.305-5 (1973, as amended 1974), 1.305-6 to $1.305-8$ (1973).

114. 207 F.2d 462 (6th Cir. 1953), cert. denied, 347 U.S. 918 (1954).

115. At present, the required holding period is nine months for taxable years beginning in 1977 , and is one year thereafter. I.R.C. $\$ 1222$. But because the basis of the dividend stock is derived by allocating to it a part of the basis of the old stock, id. $\S 307(\mathrm{a})$, the shareholders can count the period during which they held the old stock. Id. $\S 1223(5)$. Thus they might qualify for long-term capital gains treatment even if they sell the dividend stock immediately. But see id. $\S 306$ (discussed at p. 120 infra). This allocation of basis and tacking on of holding periods is, of course, merely a way of carrying out the theme of the nonrecognition provision, that the stock dividend, while involving a formal change, essentially amounts only to a continuation of an ownership interest in property.

116. Life insurance companies often have much lower effective tax rates for dividend income than do individuals. $\rightarrow$ Clark, The Federal Income Taxation of Financial In termediaries, 84 YALE L.J. 1603, 1637-57 (1975). 
no gain or loss to the latter. ${ }^{117}$ Obviously, a common stock dividend could not be used without an unwanted sacrifice of proportionate interest in residual earnings and voting power.

The taxpayers' strategy succeeded in the Chamberlin case. In 1954, one year later, Congress consciously responded ${ }^{118}$ by enacting mechanistic provisions to deal with preferred stock bailouts. ${ }^{119}$ Interestingly, Congress chose in effect to make an exception to the corporate veil decision. ${ }^{120}$ Receipt of a preferred stock dividend on common stock would continue to be a nonrecognized transaction, ${ }^{121}$ but the preferred stock would be "tainted," so that if later sold it would normally produce ordinary income to the seller. More precisely, the seller must include in ordinary income the amount that would have been dividend income if the corporation, instead of paying a preferred stock dividend, had distributed money equal to the fair market value of the preferred stock. $^{122}$ This basically simple, mechanical rule had to be qualified in a variety of ways, ${ }^{123}$ because of the various legitimate uses of preferred stock dividends. ${ }^{124}$

\section{b. Corporate Divisions and the Divisive Bailout}

Suppose that an antitrust decree forces an oil company to separate its pipeline operations from its oil producing business. It does so by means of a "spin-off," transferring the pipeline division's assets to a newly created subsidiary and distributing the subsidiary's stock to its own shareholders. After the transaction, the shareholders continue their ownership interests in the two businesses, though of course the paper evidencing their equity claims is now different. Early cases such as Rockefeller $v$. United States ${ }^{125}$ held that the distribution of such a

117. Taxpayers, of course, could vary the basic pattern described in the text; the second and third steps, for example, could be collapsed by having the distributing corporation later redeem the dividend stock from the original distributees. I.R.C. $\$ 306$ (a)(2) deals with this variation of the preferred stock bailout.

118. See S. ReP. No. 1622, 83d Cong., 2d Sess. 46, 241-46 (1954) (discussing Chamberlin and ways of closing loophole of preferred stock bailout).

119. I.R.C. $§ 306$.

120. See S. ReP. No. 1622, 83d Cong., 2d Sess. 241 (1954) (under new § 306, "the original recipient of the dividend stock is, in general, taxed on its disposition as if there had been a cash, rather than a stock, distribution to him in the first instance").

121. The various exceptions to the general rule that stock dividends are not taxable do not include the case of a simple dividend of preferred on common stock. See I.R.C. $\S \S 305(\mathrm{a})$ (general rule), (b), (c) (exceptions).

122. Id. $\S 306(\mathrm{a})(\mathrm{l})(\mathrm{A})$.

123. Id. $\S 306(\mathrm{~b})$.

124. $: \rightarrow$ Cohen, Surrey, Tarleau \& Warren, A Technical Revision of the Federal Income Tax Treatment of Corporate Dislributions to Shareholders, 52 Colum. L. REv. 1, 11-14 (1952); S. REP. No. 1622, 83d Cong., 2d Sess. $241-46$ (1954).

125. 257 U.S. 176 (1921). 
"spun-off" subsidiary's shares to the original company's shareholders should be recognized as a taxable transaction. The cases were decided in the absence of express statutory treatment of spin-offs, and they prompted Congress to legislate that such corporate separations be given nonrecognition treatment. ${ }^{126}$ The rationale behind Congress's action was that such divisions were mere business readjustments undertaken for good nontax reasons. ${ }^{127}$ In the typical manner of such developments, the language of the early legislation was simple. ${ }^{128}$

Taxpayers soon thought to combine this nonrecognition provision with the corporate veil decision. They devised the "divisive bailout," which typically involves a corporation $(X)$ that has prospered but has accumulated earnings instead of paying them out as dividends. Suppose that $X$ has invested most of the retained earnings in marketable securities issued by other entities. The shareholders of $X$ are concerned that an accumulated earnings tax may be imposed if the marketable securities are not somehow taken out of the corporation. Instead of having $X$ pay them out as dividends in kind, taxable as ordinary income, they employ a tax-free spin-off. They cause $X$ to transfer the marketable securities to a newly formed, wholly owned subsidiary $(S)$ as a nontaxable contribution to capital or in a nontaxable exchange of assets for $S$ stock. ${ }^{129}$ All the shares in $S$ are then distributed to the $X$ shareholders. The latter hope that receipt of the $S$ shares is nontaxable as part of a nonrecognized corporate division. They then sell the $S$ shares to an outsider $(B)$ who wants the marketable securities. The

126. Revenue Act of 1924, ch. 234, $\S \S 203(\mathrm{c}),(\mathrm{h})(\mathrm{l})(\mathrm{B}), 43$ Stat. 256-57.

127. See H.R. REP. No. 179, 68th Cong., 1st Sess. 14 (1924) (intent to harmonize treatment of spin-offs with that of split-ups). The prior law's partial definition of a "reorganization" (which qualified for nonrecognition treatment) did not clearly cover a transfer of property by one corporation to another, immediately after which the first corporation or its stockholders (or both) were in control of the transferee corporation (a "spin-off"). See Revenue Act of 1921, ch. 136, § 202(c)(2), 42 Stat. 230 ("reorganization" includes (1) merger or consolidation, (2) recapitalization, and (3) mere change in identity, form or place of incorporation). The legislative history of the 1924 statute describes spin-offs as a "common type of reorganization" that "clearly" should be included in the provisions for nonrecognition of corporate reorganizations. H.R. REP. No. 179, 68th Cong., 1st Sess. 16 (1924).

128. Compare Revenue Act of 1924, ch. 234, $\S \S 203(\mathrm{c}),(\mathrm{h})(1)(\mathrm{B}), 43$ Stat. 256-57 (several paragraphs relatings to divisions) with, e.g., I.R.C. $\$ \S 368(\mathrm{a})(1)(\mathrm{D}), 355,356,358,362$ (current Code provisions relating to divisions).

129. When a shareholder contributes new capital to his corporation, he simply increases the amount of his investment and therefore has no taxable gain. Even when he receives new shares in exchange for the property contributed, any gain he may have is not recognized if he is in control of the corporation after the transfer, since in that case he will have sufficient continuity of interest in the transferred property to warrant nonrecognition. I.R.C. § 351. See p. 125 infra. Gain or loss to the transferee corporation is not recognized when it issues stock in exchange for contributed property. Id. $\S 1032(a)$. 
$X$ shareholders hope to receive capital gains treatment on the sale ${ }^{\mathbf{1 3 0}}$ by virtue of the corporate veil decision. $B$ then liquidates $S$ in order to get the marketable securities. Assuming that he has paid a fair price for the $S$ stock, he will have no gain or loss on the liquidation and thus is not concerned that a liquidation is a taxable transaction. The selling shareholders, despite their favorable tax treatment, have not sacrificed their proportionate interests in the real business of $X$.

The landmark case of Helvering v. Gregory ${ }^{131}$ involved essentially this sequence of events. To defeat the divisive bailout, both the circuit court and the Supreme Court attempted to distinguish between true corporate divisions that deserved nonrecognition treatment (e.g., Rockefeller), and disguised corporate dividends that should be taxed as ordinary income (e.g., Gregory). They rose to the task and created one of the most protean judicial doctrines in the tax law: ${ }^{132}$ because the spin-off lacked a "business purpose," it would not qualify as a nontaxable corporate division within the intention of the statute. Gregory did not modify the corporate veil decision, as did Congress's response to the preferred stock bailout, by "tainting" the spun-off stock to deny it the status of a capital asset for purposes of later sale or redemption. Rather, it modified the nonrecognition decision itself by enunciating a precondition for its application. This suggests that the facial plausibility of a variety of remedial approaches to a problem injects a measure of indeterminancy into cultural evolution.

Congress quickly reacted to the Gregory case by reducing all spinoffs to the status of ordinary distributions, an extreme position from which it later retreated. ${ }^{133}$ Gregory's uncertain and amorphous business purpose doctrine persisted, and later, in order to ameliorate the attendant insecurity in the tax culture, Congress enacted yet more Code provisions in an effort to mechanize the rules for preventing the divisive bailout while permitting nonrecognition of legitimate cor-

130. Because of the Code's principle of tacking on the holding period when stock basis is allocated to new stock, see note 115 supra, the shareholders might be able to sell their $S$ shares immediately. Besides receiving capital gains treatment, they may also offset some of their old basis in the $X$ stock against the gain on sale of $S$ shares. See I.R.C. $\S 358(\mathrm{~b})(2),(\mathrm{c}) ; i d$. $\S 1223(1)(B)$.

131. 69 F.2d 809 (2d Cir. 1934), aff'd, 293 U.S. 465 (1935).

132. See genera $\rightarrow$ Chirelstein, Learned Hand's Contribution to the Law of Tax Avoidance, 77 YALE L.J. 440 (1968).

133. Before the Supreme Court affirmed the Second Circuit's reversal of the Tax Court's decision in favor of Mrs. Gregory, 27 B.T.A. 223 (1932), rev'd, 69 F.2d 809 (2d Cir. 1934), aff'd, 293 U.S. 465 (1935), Congress had enacted a provision reducing spin-offs to ordinary distributions. See BitTKer \& Eustice, supra note 3, at 13-6. In 1951 Congress relented and provided for tax-free spin-offs under certain conditions. Revenue Act of 1951, ch. 521, § 317(a), 65 Stat. 493. See Bittker \& Eustice, supra note 3, at 13-6 to 13-7. 
porate divisions. ${ }^{134}$ It did not, however, obviate the business purpose doctrine; the latter is still used as a judicial safeguard against transactions that conform to the letter but not to the reason of the law. ${ }^{135}$ The current statutory result is notable principally for its requirement that the distributing company and the company whose stock is distributed both be engaged, immediately after the distribution, in an active trade or business with at least a five-year operating history. ${ }^{136}$ This requirement and the other rules of the section have in turn produced an ample harvest of case law. ${ }^{137}$

\section{c. Combinatory Reorganizations and Recapitalizations and the Security Bailout}

A simple recapitalization-a reshuffling for good business reasons of the capital structure of a single corporation-has long been considered a nonrecognition transaction. ${ }^{138}$ Treating the combination by merger of two previously unrelated businesses as a nonrecognition transaction involves greater conceptual boldness and a more liberal tax policy. Though it is true that in a simple merger ${ }^{139}$ shareholders of each merging corporation continue in new form their interest in their old corporation's business enterprise, it is also true that they acquire for the first time an interest in the business enterprise of the other corporation. Concurrently, they lose part of their interest in their original corporation's business, for they now must share it with shareholders of the other corporation. But the degree of continuity of interest in mergers apparently satisfied Congress, for it decided to treat both statutory and practical mergers as nonrecognition transactions. ${ }^{140}$ The temptations to taxpayers accordingly multiplied.

Since exchange of stock or securities for other stock or securities of one's own corporation (in a recapitalization) or of another corporation a party to a reorganization (for example, a merger) were to be nontaxable transactions, ${ }^{141}$ some taxpayers hit upon the idea of the "secu-

134. Compare the language of Internal Revenue Code of 1939, $\S 112(b)(11)$ (spin-off provision enacted by Revenue Act of 1951, ch. 521, § 317(a), 65 Stat. 493) with the more elaborate provisions of I.R.C. § 355. See also Estate of Parshelsky v. Commissioner, 303 F.2d 14 (2d Cir. 1962) (extended historical review and analysis of I.R.C. $\$ 112(\mathrm{~b})(11)$ ).

135. See BitTKer \& Eustice, supra note 3, at 13-36 to 13-38.

136. I.R.C. $\$ 355(\mathrm{a})$, (b).

137. See Annot., [1977] 3 STAND. FED. TAX REP. (CCH) II 2517.05-.93 (1976).

138. Revenue Act of 1921, ch. 136, $\$ 202(\mathrm{c})(2), 42$ Stat. 230.

139. By "simple merger" is meant one in which all common shareholders of the merging corporation receive nothing but common shares of the surviving corporation, the old common shareholders of which continue to be common shareholders in the survivor.

140. Revenue Act of 1921, ch. 136, $\S 202(c)(2), 42$ Stat. 230.

141. Id. 
rity bailout." Consider, for example, a simplified version of the facts in the well-known case of Bazley $v$. Commissioner. ${ }^{142}$ A close corporation has a large amount of accumulated earnings and profits. The sole shareholder adopts a plan of "recapitalization," according to which he exchanges all his common stock for new common stock and bonds. He treats the exchange as a nonrecognition transaction. He later either sells the bonds, has them redeemed, or waits until the principal amount is repaid at maturity, and claims capital gains treatment on the net proceeds. ${ }^{143}$ After these transactions, the shareholder will continue to have the same proportionate interest in the residual earnings of the enterprise and the same voting power; he will not have made the usual sacrifice needed for a permissible bailout.

In the Bazley case, Justice Frankfurter dealt with this scheme by accepting the Tax Court's conclusion that the transaction was merely a vehicle for conveying earnings and profits out of the corporation. ${ }^{\mathbf{1 4 4}}$ It was therefore not a "reorganization" within the meaning and purpose of the income tax statute, but rather a taxable transaction. He observed that had the taxpayers caused their corporation to issue the debentures directly, the distribution clearly would have been taxable, and that the result should not be different merely because the debenture dividend was folded into an unrelated modification of the capital accounts. ${ }^{145}$

Inevitably, Congress moved to codify a more concrete barrier to the security bailout. ${ }^{146}$ Instead of endorsing the Bazley Court's finding that in effect the scheme was not a legitimate "reorganization," it enacted a mechanized variation, which provides that if a reorganization exchange involves receipt of securities having a principal amount in excess of the principal amount of securities given up (if any), then the excess principal amount will be treated as taxable boot to the recipient. Ordinarily, the boot will be taxed as ordinary income to the ex-

142. 331 U.S. 737 (1947).

143. For the basis of the bonds received in the recapitalization, see Revenue Act of 1921, ch. 136, § 202(d), 42 Stat. 230 (current version at I.R.C. $\S 358(a)(1)$, (b)(1)). In essence, the sharcholder's basis in his old shares is neither increased nor decreased as a result of the transaction, and the total basis is transferred to the new stock and bonds and allocated among them. Since by hypothesis the shareholder's total investment has increased greatly in value, the market value (and face value) of the new bonds will substantially exceed their basis. Thus, when the bonds are sold or redeemed, the shareholder will have taxable gain, which is, however, generally capital gain. See id. § 1232 (a)(1), (2)(A).

144. 331 U.S. at 743 .

145. Id. at 742 .

146. I.R.C. $\S \S 354(\mathrm{a})(2), 356(\mathrm{~d})$ (originally enacted as Internal Rev. Code of 1954, ch. $1, \S \S 354(\mathrm{a})(2), 356(\mathrm{~d}), 68 \mathrm{~A}$ Stat. 112, 115-16). 
tent of the distributing company's earnings and profits. ${ }^{147}$ The rule applies to reorganizations generally, not just to recapitalizations.

\section{d. Incorporations and the Liquidation-Reincorporation Bailout}

Transfers by shareholders to a newly formed corporation, or to one already in business, in exchange for stock or securities of the corporation have long been treated as nonrecognition transactions when the transferors have control of the corporation immediately after the transfer. ${ }^{148}$ Again, the control test reflects the continuity of interest notion: when the transferors' ownership interest in the corporation is quite large, they can be deemed "in substance" to be continuing their interest in the transferred assets and merely changing the form of their ownership. ${ }^{149}$

As might be expected, some taxpayers combined an expression of the corporate veil decision with an incorporating transaction to produce an attractive bailout. One important procedure they developed might be called the straightforward ${ }^{150}$ version of the "liquidationreincorporation bailout." In this scheme, the manifestation of the veil principle that is used is the complete liquidation provision. In the most blatant example, a corporation possessing excess cash, substantial earnings and profits, and depreciable operating assets, some of which have appreciated greatly in value, completely liquidates. Under section 331, which brings liquidations under the corporate veil principle, taxpayer-shareholders pay a capital gains tax on the difference between the value of what they receive in liquidation and the basis of their stock. $^{151}$ In return for this, however, they achieve three significant tax

147. See I.R.C. $\$ \S 356(\mathrm{a})(2)$, (b), (d). Section $356(\mathrm{a})(2)$ provides that gain upon exchange will be treated as a dividend if the exchange "has the effect of the distribution of a dividend." In interpreting this provision, courts have focused on such factors as the existence of corporate earnings and profits, the pro rata nature of the distribution of "boot," and the effect on the shareholder's proportionate ownership interests. See SURREY \& WARren, supra note 3 , at 815 (citing cases). See generally id. at 810-27.

148. Revenue Act of 1921, ch. 136, $\S 202(c)(3), 42$ Stat. 230 (current version at I.R.C. § 351$)$.

149. See S. REP. No. 275, 67th Cong., 1st Sess. 11-12 (1921), reprinted in 1939-2 C.B. $181,188-89$ (provisions designed to facilitate business "readjustments," also to increase revenues "by preventing [taxpayers] from taking colorable losses ... in fictitious exchanges”); Portland Oil Co. v. Commissioner, 109 F.2d 479, 488 (1st Cir. 1940) (purpose of control test to prevent recognition where there has been "mere change in the form of ownership" but not real cashing in of gain or closing out of losing venture).

150. The scheme described in the text is termed "straightforward" because it literally involves a liquidation and a reincorporation in that temporal sequence. Related schemes turn on the bailout possibilities of liquidations and the nonrecognition treatment afforded transfers to controlled corporations, but are less obvious. See note 156 infra.

151. I.R.C. $\S 331$ (total amount received in liquidation treated as though received in exchange for stock). 
objectives. The excess cash is in their hands, ready to be spent, without their having paid an ordinary income tax. The corporation's earnings and profits account has been eliminated because the corporation has ceased to exist. ${ }^{152}$ And after distribution, the depreciable assets are valued at fair market value for depreciation purposes, even though only a capital gains tax has been paid as the price of the step-up in basis. ${ }^{153}$ As tax practitioners well know, the present cost of the capital gains tax may be outweighed by the discounted present value of the tax savings that results from the extra depreciation deductions made possible by the step-up in basis. Typically, this will occur when the assets are relatively short-lived, the business's tax rate is reasonably high, and the business is expected to generate sufficient profits for the deductions to be usable. ${ }^{154}$ Having reaped the benefits of complete liquidation, the shareholders can simply reincorporate in a nonrecognized transaction; ${ }^{155}$ they transfer the operating assets but not the cash to a newly formed corporation in exchange for its stock. They can then continue their business as if nothing had happened except the receipt of tax advantages. ${ }^{156}$ Ritual and prayer are thus employed

152. Eliminating the "earnings and profits" account from an enterprise's tax-accounting records is valuable because the account represents potential ordinary income tax liability to the shareholders: except as otherwise provided (e.g., in liquidations), distributions are deemed to come out of earnings and profits to the extent thereof, and distributions out of earnings and profits are dividends taxable at ordinary rates. See pp. 100-01 \& note 36 supra.

153. I.R.C. $\$ \S 331,334(\mathrm{a}), 336$. That there is only one capital gains tax on distributions of appreciated property depends upon the seventh (General Utilities) principle, as expressed in id. $\S 336$. See pp. 130-35 infra. The description of the liquidation-reincorporation scheme in the text thus invokes that principle as well as the fifth and sixth. But notice that because of the first two tax objectives, the scheme might be very worthwhile even if the values of the assets were exactly equal to their bases. The advantage of obtaining a step-up in asset bases is mentioned at this point only to give a sense of the full tax-avoidance potential of the scheme.

154. Other versions of the liquidation-reincorporation bailout become available when the taxpayers do not seek a step-up in asset bases. For example, there might be a transfer of operating assets to a new subsidiary (nonrecognized, see I.R.C. $§ 351$ \& notes 148-49 supra), followed by liquidation of the parent; shareholders of the latter receive both the excess cash and stock in the subsidiary, which now conducts the business. See example (3) in note 156 infra.

155. I.R.C. $§ 351$. See p. 125 \& note 149 supra.

156. It may help to contemplate some numerical hypotheticals. Suppose that $X$ Corporation has the following tax balance sheet:

\section{Assets}

Cash

Operating Assets (basis)

\section{$\$ 40$}

60

\section{Liabilities}

Legal Capital

Earnings \& profits
$\$ 50$

50

The cash is not necessary for the operations of the company. The sole shareholder $(S)$ has a basis in his stock of $\$ 60$. The fair market value of the operating assets is $\$ 80$.

(1) Straightforward Liquidation-Reincorporation. (a) $X$ Corporation liquidates. $S$ pays a capital gains tax on $\$ 60$, the difference between the value of what he received (\$80 of assets $+\$ 40$ cash) and the basis in his stock $(\$ 60)$. I.R.C. $\$ 331$. The operating assets now 
to earn indulgences from one's appointed stay in the tax law's purgatory. It was a marvelous idea indeed. If the device were permitted to work, then any going concern in corporate form would be free to absolve itself, from time to time, of its profit-blighting tax attributes at a relatively inexpensive cost. And it could do so without actually ceasing to do business in the corporate form or affecting its shareholders' continuing interests in the business. ${ }^{157}$

have a basis of $\$ 80 . I d . \S 334(\mathrm{a}) . \mathrm{X}$ pays no tax. Id. $\S 336$. (b) $S$ then transfers the operating assets but not the cash to newly formed $Y$ Corporation, in return for all its stock. The transfer is not taxed, id. $\S 351 ; Y$ 's basis in the assets is $\$ 80$, id. $\S 362(\mathrm{a})(1)$; and $S$ 's basis in the $Y$ stock is $\$ 80, i d$. $\S 358(\mathrm{a})$. If $S$ had reached the same pretax economic result by the nondevious route of simply having $X$ distribute the cash, he would have paid an ordinary income tax on $\$ 40$, and the operating assets would have kept their low basis of $\$ 60$.

(2) Section 337 Sale-and-Liquidation Variant. (a) $S$ forms $Y$ Corporation and contributes $\$ 80$ for its stock. The transaction is not taxed. Id. $\S 351$. Alternatively, $Y$ may be a preexisting brother corporation of $X$ that has accumulated both excess cash and earnings and profits of $\$ 80$, which $S$ desires to bail out along with $X$ 's $\$ 40$ of cash. (b) $X$ adopts a plan of complete liquidation and sells all the operating assets to $Y$ for $\$ 80$. The sale is not taxed. Id. $\S 337$. Like id. $\S 336$, see note 153 supra, this section stems from the seventh principle. See pp. 130-35 infra. (c) $X$ then distributes its assets, which are now all in the form of cash (the original $\$ 40$ and the $\$ 80$ received for the operating assets), in liquidation. $S$ pays a capital gains tax on $\$ 60$ (X's $\$ 120$ of cash minus $S$ 's $\$ 60$ basis). I.R.C. $\S 331 . Y$ has a cost basis of $\$ 80$ for the $X$ assets. The tax results here are the same as in example (1). Note that the $\$ 80$ pumped into $Y$ comes right back to $S$; he therefore might arrange a temporary and quite safe loan to effectuate the scheme. If the $\$ 80$ represented past earnings of $Y$, then the amount of tax avoidance is even greater; in effect, $Y$ 's cash, as well as $X$ 's, is bailed out, even though the tax burden is the same as in example (1).

(3) Transfer-to-Subsidiary-and-Liquidation Variant. Assume now that the fair market value of $X$ 's operating assets is $\$ 30$, significantly less than their basis $(\$ 60)$. S still wants to bail out the cash. But he will not want a stepdown in the basis of the operating assets, so long as the negative present value of the decrease in future depreciation deductions is greater than the tax savings from reduction of his capital gain on liquidation-from $\$ 60$, as in examples $(1)$ and $(2)$, to $\$ 10$ (\$30 of assets $+\$ 40$ cash $-\$ 60$ stock basis), as in this example if the straightforward scheme were employed. So $S$ concocts a new, and purer, scheme. (a) $X$ transfers all its operating assets but not the cash, to a newly formed, wholly owned subsidiary $(Y)$ in exchange for all of $Y$ 's stock. The transaction is not taxed. Id. $\S 351$. (Again, $Y$ could be a preexisting subsidiary.) $Y$ takes $X$ 's high basis of $\$ 60$ in the operating assets. Id. $\S 362(\mathrm{a})$. (b) $X$ then liquidates and distributes the $Y$ stock and $\$ 40$ to $S$. $S$ pays a capital gains tax on $\$ 10$ ( $\$ 30$, the value of the $Y$ stock, plus $\$ 40$, the cash, minus $\$ 60, S$ 's basis in the $X$ stock). $I d$. $\$ \$ 331,334$. It should be obvious that when the value of the assets has fallen below their bases, the taxpayer will always prefer this scheme to the straightforward one, even when the tax trade-offs make the latter a better course than doing nothing, because this third scheme will trigger the same present tax cost but will not result in a step-down in asset bases.

The above discussion assumes, of course, that none of the schemes would be attacked successfully by the Service.

157. The reader may have noted that the tax advantages of the first two schemes described in the preceding footnote do not depend upon the nonrecognition rule of I.R.C. $\$ 351$ (transfers to controlled corporations), which was invoked in all three examples. In the first scheme ("straightforward liquidation-reincorporation"), the assets transferred to the new corporation received (at the time of liquidation) a step-up in basis to fair market value. Consequently, taxing the exchange of assets for the new company's stock would not change the result, since the transferring individual would simply have no gain. Similarly, 
Unfortunately for taxpayers, the courts were not disposed to take all of this passively. By applying sheer willpower to the task of contorting statutory language in five or six different places, they have managed to categorize some liquidation-reincorporation sequences as so-called " $D$ " reorganizations. ${ }^{158}$ Such reorganizations qualify for non-

in example (2) ("section 337 sale-and-liquidation variant"), the $\$ 80$ contribution for new stock would produce no gain to the shareholder, even if it were recognized for tax purposes. The taxpayer's objective in the third example ("transfer to subsidiary-and-liquidation variant”), however, would be defeated if $\$ 351$ did not apply, for only nonrecognition prevents a stepdown in basis of the property transferred to the subsidiary.

These reflections prompt a second look at the propriety of calling the liquidationreincorporation schemes "nonrecognition bailouts." The first two schemes, unlike the third, depend not upon nonrecognition of incorporating transactions, but upon the decisions to assimilate liquidations to stock sales and to step up the basis of distributed property to its full fair market value even when the distributee has been taxed only at capital gains rates. From a more revealing perspective, however, all three schemes result from the Code's failure to provide appropriate nonrecognition treatment for all series of transactions involving substantial continuity of ownership interest. The real fault lies in the reorganization provisions, which of course are nonrecognition provisions; they fail to encompass explicitly all the events that, in view of their underlying rationale, they should cover. See note 158 infra (discussing resulting problems and judicial attempts to cope with this de facto (but presumably unintended) electiveness of nonrecognition rules by classifying schemes as " $D$ " or " $F$ " reorganizations, which are nonrecognized but subject to rules that eliminate tax avoidance). In this light, "nonrecognition bailouts" is an appropriate term for the liquidation-reincorporation schemes.

158. A " $D$ " reorganization is defined as

a transfer by a corporation of all or a part of its assets to another corporation if immediately after the transfer the transferor, or one or more of its shareholders (including persons who were shareholders immediately before the transfer), or any combination thereof, is in control of the corporation to which the assets are transferred; but only if, in pursuance of the plan, stock or securities of the corporation to which the assets are transferred are distributed in a transaction which qualifies under section 354,355 , or $356 \ldots$.

I.R.C. $\$ 368(a)(1)(D)$. Sections 354,355 , and 356 specify the conditions for nonrecognition treatment of the distribution of stock or securities in the transferee corporation to the shareholders of the transferor corporation. If the liquidation-reincorporation sequence of example (1) in note 156 supra is successfully characterized as a 'D' reorganization, the adverse consequences noted in the text will follow. But to invalidate the bailout exemplified by the example (1) sequence by resort to the statutory provisions, a court must overcome substantial barriers.

(1) Section $368(a)(1)(D)$ speaks of a transfer of assets by one corporation to another. But, if the scheme is taken at face value, it is $S$, not $X$, who makes the transfer to $Y$. A court could respond that $X$ "indirectly" or "in substance" made the transfer, and that $S$ served as a mere "conduit."

(2) Section $368(a)(1)(D)$ requires that the transferor (now assumed to be $X$ ) or its shareholders $(S)$ be in "control" $(80 \%$, see id. $\S 368(\mathrm{c}))$ of the transferee immediately after the transfer. But $S$, if he were as cleverly advised as some actual taxpayers, might arrange to have outside investors buy $21 \%$ of all the stock to be issued by $Y$, prior to the transfer of $X$ 's operating assets to $Y$ for the other $79 \%$ of $Y$ stock. This clearly evades the statutory definition.

(3) Section $368(a)(1)(D)$ also requires that, in pursuance of the plan, stock or securities of the transferee corporation $(Y)$ be "distributed" in a transaction qualifying under I.R.C. $\S \S 354,355$, or 356 . The context and ordinary Code usage of the term "distributed" imply a distributor other than $Y$ ( $Y$ is said to "issue" its own shares), and in this case the only candidate is $X$. But $X$ has not distributed $Y$ 's shares. A court could respond that the transaction was virtually the same as if $X$ were technically a distributor. 
recognition treatment, but the specific consequences of nonrecognition vitiate the advantages of the bailout scheme: the excess cash that the shareholders receive in the liquidation-reincorporation game is considered either taxable boot or a functionally unrelated distribution of cash from a continuing business; the earnings and profits account of the "liquidated" corporation is not destroyed but carries over to the new legal entity; and the basis of the operating assets likewise carries over unchanged.159 But taxpayers, predictably, did not give up so easily. They devised new versions of the liquidation-reincorporation bailout and worked diligently at disguising and complicating all the simple variations. ${ }^{160}$ The resultant body of case law ${ }^{161}$ is somewhat grotesque but vaguely titillating. If the pattern displayed in the other

(4) Fitting this constructive distribution of $Y$ shares by $X$ under $\S 355$ is impossible because of the active business requirements of that section, see id. $\S 355$ (b). Section 356 applies only if the transaction would qualify under $\S 354$ or $\S 355$ but for the distribution of boot, see $i d$. $\S 356(a)(1)(A)$. Thus the constructive distribution must qualify, if at all, under $\S 354$. This section requires an exchange (by the shareholder in the transferor corporation) of stock or securities in one corporation for those of another pursuant to the reorganization. $I d$. $\S 354(\mathrm{a})(1) . S$, however, exchanged assets, not $X$ stock, for the $Y$ stock. A court might say that, when the steps of the scheme are viewed as a whole, or in terms of their net result, there was such an exchange.

(5) Section $354(\mathrm{~b})(1)$ requires in the case of a " $D$ " reorganization that $Y$ acquire "substantially all of the assets" of the constructive transferor, $X$. But $Y$ did not acquire $X$ 's $\$ 40$ of cash, which is substantial in relation to the operating assets (valued at $\$ 80$ ). A court might interpret the statute to mean "substantially all of the operating assets"-a move that would give it trouble in the ordinary reorganization case, in which the Service often argues quite rightly that a challenged transaction does not deserve nonrecognition treatment. Alternatively, a court might say that the liquidating distribution of cash must be deemed a functionally unrelated cash dividend paid by $X$ prior to the constructive transfer of operating assets to $Y$.

(6) Section $354(\mathrm{~b})(\mathrm{l})(\mathrm{B})$ requires that the $Y$ stock "received by such transferor" (i.e., $X)$ be distributed in pursuance of the plan. This might be read to imply that $X$ must in fact have received some $Y$ stock. A court might answer that there was constructive receipt, or that the language should be read without such implication, as if it said "the stock ... received by such transferor (if any)...."

The above analysis presents a rather full listing of the problems raised by a careful, literal reading of the statute. In practice, courts have exhibited varying degrees of thoroughness when responding to, sliding over, or confusing these problems in order to frustrate liquidation-reincorporation bailouts. See, e.g., Survaunt v. Commissioner, 162 F.2d 753 (8th Cir. 1947); Bard-Parker Co. v. Commissioner, 218 F.2d 52 (2d Cir. 1954), cert. denied, 349 U.S. 906 (1955); Davant v. Commissioner, 366 F.2d 874 (5th Cir. 1966), cert. denied, 386 U.S. 1022 (1967) (both D and F reorganization found). See generally Hjorth, Liquidations and Reincorporations-Before and After Davant, 42 W ASH. L. ReV. $737(196 \rightarrow$ Lane, The Reincorporation Game: Have the Ground Rules Really Changed? 77 Harv. L. Rev. 1218 (1964).

159. See I.R.C. $\$ 356(\mathrm{a})(2)$ (dividend treatment of boot); id. $\S 381(\mathrm{c})(2)$ (earnings and profits carryover); id. $\S 362$ (b) (basis carryover); SurReY \& WARREN, supra note 3, at 92124 (discussion of cases dealing with possibility of viewing distributed cash as "functionally unrelated" to reorganization).

160. Davant v. Commissioner, 366 F.2d 874 (5th Cir. 1966), cert. denied, 386 U.S. 1022 (1967), provides a magnificent example. The taxpayers used the basic pattern discussed in example (2) in note 156 supra, but complicated it by injecting a straw-man intermediary.

161. See Annot., [1977] 3 Stand. Fed. Tax ReP. (CCH) I 2551.2694 (1976). 
three nonrecognition areas holds true, the next major step will be an attempted legislative solution to the liquidation-reincorporation problem. Barring developments that might moot the problem, ${ }^{162}$ this step, by all precedent, should occur.

\section{Corporate distributions in kind shall not create taxable gain or} loss to the corporation (The General Utilities principle)

In 1935, in the fateful case of General Utilities \& Operating Co. $v$. Helvering, ${ }^{163}$ the Supreme Court decided that a certain dividend distribution of appreciated property did not result in taxable gain to the distributing corporation. Closely read, the opinion does little more than reject the argument that when a corporation declares a dividend in a specified dollar amount and then pays it by distributing appreciated property of equivalent value, it realizes income by virtue of the doctrine that a discharge of indebtedness yields income. ${ }^{164}$ Courts, however, soon interpreted the case as standing for the broader "General Utilities principle" expressed above. ${ }^{165}$ The effects of the holding upon the corporate tax culture, hardly foreseeable by the Supreme Court in 1935, have been great.

The eventual statutory embodiments of the decision represent its first set of consequences. After years of vigorous but usually unsuccessful attempts by the Service to prevent judicial application of the principle, ${ }^{166}$ Congress, in the 1954 Code, adopted it not only for distributions from continuing businesses but also for liquidating distributions. $^{167}$ Both provisions are overburdened with exceptions ${ }^{168}$ and are explicitly subject to various depreciation recapture and other recapture rules. ${ }^{169}$ In addition, the courts, in wavering and uncertain

162. Full-scale integration of the corporate and individual income taxes to eliminate the double tax on corporate-source income, together with elimination of the capital gains preference, would be one example.

163. 296 U.S. 200 (1935).

164. Id. at 204, 206. The Commissioner sought to tax as income to the corporation the difference between its basis in the property distributed (stock in another corporation, acquired at $\$ .10$ per share) and the value of the property when distributed $(\$ 56.125$ per share). Id. at 201, 203.

165. See Surrey \& WARren, supra note 3, at 344 .

166. Id.; BitTKer \& Eustice, supra note 3, at 7-40.

167. I.R.C. $\S \S 311$ (continuing businesses), 336 (liquidations).

168. Section 311 contains elaborate exceptions for distributions involving "last-in, first-out" (LIFO) inventory, liabilities in excess of the basis of the distributed property, and appreciated property used to redeem stock; sections 311 and 336 both incorporate the $\$ 453(\mathrm{~d})$ exception for installment obligations.

169. When depreciation deductions or other amortizations of the purchase price of property have been taken at an accelerated rate by virtue of provisions such as id. $\$ 167$ $(b)(2)$, (b)(3), (k), the Code often specifies that the sale or other disposition of the property will cause part of the previously deducted amounts to be included-"recaptured" is the tax jargon-in the seller's income. See, e.g., id. $\$ \S 1245,1250$. 
fashion, have applied certain judicially created doctrines from other areas of tax law to distributions in kind. ${ }^{170}$ Moreover, the provision governing liquidations has given rise to yet another taxpayer scheme: under the not infrequently successful "straddle" technique, a corporation that wishes to liquidate sells its depreciated property in order to recognize a loss in its last taxable year, but keeps its appreciated property for distribution in kind to the shareholders; the corporation thereby avoids recognition of the gain on such property. ${ }^{171}$

The second set of consequences grew directly from the courts' adoption of the General Utilities principle. Applying the rule to liquidations required a distinction between sales made by the corporation, which would be taxable to it, and sales made by the shareholders after receiving the property in liquidation, which would invoke no tax at the corporate level. Attempts to draw this distinction proved quite difficult in concrete situations ${ }^{172}$ and underscored the arbitrariness and potential unfairness of making the tax treatment depend upon whether the shareholders were sufficiently well advised to follow the magically correct temporal sequence. Congress, again responding to a problem with mechanical rules, enacted a provision that makes it generally irrelevant whether the corporate assets were sold before or after dissolution and liquidation. ${ }^{173}$ The section provides roughly that the corporation shall not realize gain or loss on sales of property within the twelve-month period following the adoption of a plan of complete liquidation. But the ghost was not neatly exorcised, for it was thought necessary to have exceptions or special rules for inventory not sold in bulk, installment obligations, collapsible corporations, liquidations of subsidiaries, and certain minority shareholders. ${ }^{174}$ More-

170. See, e.g., Commissioner v. First State Bank, 168 F.2d 1004, 1008 (5th Cir.), cert. denied, 335 U.S. 867 (1948) (decided prior to enactment of I.R.C. § 311) (anticipatoryassignment-of-income doctrine applied to avoid application of General Utilities principle), followed in Commissioner v. First State Bank of Matador, 172 F.2d 224 (5th Cir. 1949) (per curiam); Tennessee Carolina Transp., Inc. v. Commissioner, 65 T.C. 440, 446-48 (1975), appeal docketed, No. 76-2496 (6th Cir., Aug. 4, 1976) (tax benefit rule applied to straight liquidation of subsidiary, despite I.R.C. $\S 336$ ). But cf. Commissioner v. South Lake Farms, Inc., 324 F.2d 837, 840 (9th Cir. 1963) (I.R.C. $\$ 336$ mandates nonrecognition of gain, despite "windfall" and despite $i d$. $\S 446(\mathrm{~b})$, which authorizes government recomputations of taxpayer's income using accounting methods that will "clearly reflect income").

171. Commissioner v. South Lake Farms, Inc., 324 F.2d 837 (9th Cir. 1963), is an infamous straddle case.

172. Compare Commissioner v. Court Holding Co., 324 U.S. 331 (1945) (formal sale by stockholders taxable as actual sale by corporation) with United States v. Cumberland Pub. Serv. Co., 338 U.S. 451 (1950) (sale by stockholders not taxable as sale by dissolved corporation).

173. Internal Rev. Code of 1954, ch. 736, $\S 337,68 \mathrm{~A}$ Stat. 106 (current version at I.R.C. $§ 337)$.

174. I.R.C. $\S 337(\mathrm{~b})$, (c). Collapsible corporations are discussed at pp. 132-35 infra. 
over, because the twelve-month period begins to run only after the occurrence of a formal event-the adoption of a plan-it is practically elective for taxpayers and thus has generated its own straddling technique. ${ }^{175}$ Perhaps because of the tax-avoidance possibilities it presents, it too has become subject to various exceptions. ${ }^{1 i 6}$

A final consequence of the General Utilities principle is that, in conjunction with the corporate veil principle, it has generated a third kind of problematic bailout, the "General Utilities bailout." The General Utilities notion as embodied in the Code ${ }^{177}$ enables individual taxpayers, upon liquidation of their corporations, to obtain the appreciation in value of corporate assets at the cost of only a capital gains tax at the shareholder level, even though the stepped-up basis of some distributed property may be used to offset future ordinary income. To simplify somewhat, the principle may enable the bailout of future income, not just past, already taxed income. ${ }^{178}$

The most shocking example of this abuse of the General Utilities principle is the collapsible corporation; one might even call this third kind of bailout the collapsible bailout. To take a simple example, consider a liquor dealer who wants to purchase a special whiskey, hold it while it appreciates in value, and then sell it to retailers at a substantial profit. If he did this as a sole proprietor, sales proceeds in excess of cost and expenses would be taxed as ordinary income. If he operated in a normal corporation, he would either resort to the conventional retained earnings strategy or bear the typical double tax. Instead, the dealer forms a new corporation to which he contributes the funds to purchase the whiskey; the corporation buys the whiskey and holds it. But after the whiskey has appreciated in value and could be sold at a great profit by the corporation, the entity is liquidated. The dealer-shareholder pays a capital gains tax on the difference between the fair market value of the whiskey and his basis in the corporate stock, which reflects the whiskey's cost. The assets get a stepped-up basis, so that when the dealer himself then sells the whiskey to a retailer at fair market value, his receipt of the proceeds will produce little additional taxable income. In effect, the dealer will have converted future ordinary income into capital gains.

In the pure cases of the simple bailout and the nonrecognition bail-

175. See, e.g., City Bank of Washington, 38 T.C. 713 (1962).

176. See SURReY \& Warren, supra note 3, at 489-94.

177. I.R.C. $\S \S 311,336,337$. See pp. $130-31$ and notes 167,168 \& 173 supra.

178. Previous examples of bailout schemes covertly invoked this fundamentally different General Utilities strategy. See, e.g., the liquidation-reincorporation scheme discussed at pp. 125-27 supra. The footnotes, however, were overt. See notes 153 \& 156 supra. 
out, ${ }^{179}$ shareholders simply attempt to convert past income, that is, accumulated corporate earnings already taxed as ordinary income to the corporation, into capital gains. They are thus seeking to avoid paying the double ordinary income tax created by the separate tax and distribution principles and implemented by the dividend principle. The liquor dealer, by contrast, is trying to avoid the ordinary income tax at both the corporate and the individual levels. He seeks to use the corporate form, not just in a way that will avoid the double tax pattern (the "corporate overtax" model) and lower his taxes to those of a partner or sole proprietor (the "proprietorship" model), nor even to get the traditional undertax advantage of the retained earnings strategy (the "corporate undertax" model), but in a way that will produce a sharply lower tax burden than any one of these three traditional models of taxation. ${ }^{180}$

179. See pp. 113, 118 supra.

180. See note 43 supra (describing "corporate overtax" model); note 45 supra (describing "proprietorship" model); note 81 supra (describing "corporate undertax" model).

Assume that $S$ is a whiskey dealer and is in a marginal tax bracket of $70 \%$ for ordinary income and $25 \%$ for capital gains. He can buy a case of the special whiskey for $\$ 50$ and correctly predicts that, if he then waits a year, he will be able to sell it to $P$ for $\$ 150$ (net of expenses other than the original cost). Compare the following tax patterns:

I. Proprietorship Model

Acting as proprietor and dealer, $S$ buys the whiskey, waits a year, sells it to $P$, and therefore has $\$ 100$ of ordinary income, since the whiskey was inventory in his hands. Tax: $\$ 70$.

II. Corporate Undertax Model

$S$ incorporates, transferring assets and money to newly formed $X$ Corporation. $X$ buys the whiskey, waits a year, sells it to $P$, has income of $\$ 100$, pays a tax of $\$ 48$, and retains $\$ 52$. $S$ later bails out his retained earnings by selling $X$ stock; $\$ 52$ of his capital gain is attributable to retained earnings from the whiskey sale.

Tax: $\$ 48$ to $X(.48 \times \$ 100)$

13 to $S(.25 \times \$ 52)$

$\overline{\$ 61}$ total

III. Collapsible Patterns (successful; pre-I.R.C. § 341)

(a) Liquidation-Asset Sale Sequence. $S$ incorporates. $X$ buys the whiskey at $\$ 50$, waits a year, and then, when the whiskey is worth $\$ 150$, liquidates. Under I.R.C. $\$ \S 331$ and 336 , the only tax is to $S$ on his capital gain of $\$ 100$. Under $i d$. $\S 334(\mathrm{a}), S$ 's basis in the whiskey is $\$ 150$. He sells it to $P$ for $\$ 150$, thus realizing no further gain.

Tax: $\$ 25$ to $S$

(b) Stock Sale-Liquidation Sequence. $S$ incorporates. $X$ buys the whiskey at $\$ 50 . S$ waits a year, then sells the stock to $P$ for $\$ 150$, realizing $\$ 100$ of taxable capital gain. $P$ liquidates $X$ to get the whiskey, but, since his stock basis, $\$ 150$, equals the value of the assets received, realizes no gain.

Tax: $\$ 25$ to $S$.

IV. Collapsible Treatment: I.R.C. \$341(a).

(a) Liquidation-Asset Sale Sequence; facts as in III(a). Section 341(a) turns $S$ 's $\$ 100$ gain on liquidation into ordinary income.

Tax: $\$ 70$ to $S$ (like example I, the Proprietorship Model)

(b) Stock Sale-Liquidation Sequence; facts as in $I I I(b)$. Section 341 (a) turns $S$ 's $\$ 100$ gain on the stock sale into ordinary income.

Tax: $\$ 70$ to $S$ (like example I, the Proprietorship Model) 
The collapsible technique met with early successes in the courts, ${ }^{181}$ while Congress predictably reacted to the device with detailed statutory rules. ${ }^{182}$ The basic plan of the response seems straightforward enough. The main provision, section 341 (a), simply reverses the usual manifestation of the veil decision, that stock is to be considered a capital asset regardless of corporate-level events: for shareholders of collapsible corporations, stock sales and distributions in liquidation

V. Collapsible Treatment: I.R.C. §341(f); compare id. §337(c)(1)(A).

(a) Stock Sale-Liquidation Sequence; facts as in example III (b). Section 341(f) provides that $S$ 's $\$ 100$ gain on the stock sale will be capital gain if $X$ consents to take the difference $(\$ 100)$ between the value and the basis of the whiskey into income upon its disposition in liquidation (or sale). When $X$ liquidates, therefore, it will be taxed $\$ 48$. If $P$ was ignorant of the consent and paid $\$ 150$ for the stock, the total tax burden would be $\$ 73$ (\$25 to $S$ on the stock sale plus $\$ 48$ to $X$ upon liquidation). But if, as is customary, $P$ asked for representations and discovered the consent, he would have paid $S$ only $\$ 102$ for the stock (its value net of the foreseeable corporate tax). This means that $S$ 's capital gain would have been only $\$ 52(\$ 102-50)$, rather than $\$ 100$.

Tax: $\$ 13$ to $S$

\section{8 to $X$}

$\overline{\$ 61}$ total (like example II, the Corporate Undertax Model)

(b) Asset Sale-Liquidation-Distribution Sequence. $S$ incorporates. $X$ buys the whiskey at $\$ 50$, waits a year, adopts a plan of complete liquidation, then sells the whiskey to $P$ for $\$ 150$ and liquidates, distributing the proceeds to $S$. $S$ hopes that I.R.C. $\S 337$ will prevent gain to $X$ on the whiskey sale, and that his gain on liquidation is capital gain (total tax: \$25). But, under the Service's interpretation of the confusing relationship between $i d$. $\S 341(\mathrm{~b})$ and $i d$. $\S 337(\mathrm{c})$ (1)(A), $X$ will have $\$ 100$ of taxable income on the whiskey sale, though $S$ gets capital gains treatment on his $\$ 52(\$ 102$, the liquidating distribution of $X$ 's after-tax proceeds, minus $\$ 50$, his stock basis). Rev. Rul. 58-241, 1958-1 C.B. 179. Tax: $\$ 48$ to $X$

13 to $S$

$\$ \overline{61}$ total (like example II, the Corporate Undertax Model)

Since pattern $\mathrm{V}(\mathrm{a})$ is better for the taxpayers than either pattern in example IV, Bittker and Eustice were wrong to suggest that $\S 341(f)$ is useless when the prospective buyer knows of the consent. See Bitrker \& Eustice, supra note 3, at 12-33. The advantage of $\S 341(f)$ holds even when one assumes a perhaps more realistic $35 \%$ marginal capital gains tax rate for the taxpayer in the $70 \%$ bracket. A lower-bracket taxpayer, however, might prefer $\S 341$ (a). If his marginal rates were $60 \%$ for ordinary income and $30 \%$ for capital gains, for example, the tax result for each pattern in the hypothetical case would be as follows: I, $\$ 60$; II, $\$ 63.60$; III, $\$ 30 ;$ IV, $\$ 60 ; \mathrm{V}, \$ 63.60$. Moreover, the force of certain practical considerations ignored in the hypothetical case will vary with the facts. Subsection (f) might be favored when the corporate-level tax can be deferred for a significant period, but disfavored when collapsible status is uncertain and the taxpayer wants to gamble on not receiving either kind of collapsible treatment. Whether $\S 341(\mathbf{f})$ is better for the taxpayer than $\S 341$ (a) thus depends upon a number of factors.

181. Herbert v. Riddell, 103 F. Supp. 369 (S.D. Cal. 1952); Pat O'Brien, 25 T.C. 376 (1955).

182. Revenue Act of 1950, ch. 994, § 212(a), 64 Stat. 934 (amending Internal Rev. Code of 1939 to add $\S 117(\mathrm{~m})$ ) (current, greatly expanded version at I.R.C. $\S 341$ ). At the time Congress approved this legislation, the collapsible device had not yet been tested in the courts. An amendment dealing specifically with the collapsible problem was considered desirable in order to ensure that the scheme would not result in tax advantage in the future. See H.R. REP. No. 2319, 81st Cong., 2d Sess., reprinted in 1950-2 C.B. 380, 451. See also id. at 422-23, 449-51. 
produce ordinary income. ${ }^{183}$ Essentially, this forces the collapsible corporation's tax treatment into the proprietorship model of taxation, ${ }^{184}$ as if the shareholder had never employed the corporate form. An alternative treatment is available under section $341(\mathrm{f})$, which in effect allows the taxpayer to operate within the corporate undertax model. ${ }^{185}$ But this conceptual simplicity of the congressional response contrasts starkly with the intricacy of its operational specifications. Section 341 is the most complex provision of subchapter $\mathrm{C}$, and one of the most complex in the Code. One subsection ${ }^{\mathbf{1 8 6}}$ displays nightmarish levels of convolution. Moreover, an inquiry into the reasons for the various tests and exceptions suggests that they are not arbitrary, and that even an ideal draftsman could not be expected to write the section in a tolerably simple way without ignoring schemes for avoiding the basic rules or sacrificing demands for fairness and predictability. ${ }^{187}$ Yet despite its complexity, the legislation has neither foreclosed litigation nor prevented taxpayers from reaping substantial benefits from the collapsible device. ${ }^{188}$ Cultural evolution continues.

\section{The Power of Method in the Analysis of Reforms}

The ramifications of the seven basic decisions explored above define the legal landscape of the corporate tax culture. Yet if anything is

183. I.R.C. $§ 341(a)$.

184. Compare Pattern IV with Pattern I in note 180 supra.

185. Compare Pattern V with Pattern $I$ in note 180 supra.

186. $I d . \S 341(\mathrm{e})$.

187. See generally Bitrker \& Eustice, supra note 3, chap. 12. For additional discussions of the intricacies of $\S 341$, see Axelrad, Collapsible Corporations and Collapsible Partnerships, 1960 S. Cal. TAX Inst. $\rightarrow$ DeWind \& Anthoine, Collapsible Corporations, 56 Colum. L. Rev. 475 (1956); Goldstein, Section 341(d) and (e)-A Journey into NeverNever Land, 10 Vilc. L. Rev. 215 (1965); Hall, The Consenting Collapsible CorporationSection 341(f) of the Internal Revenue Code of 1954, 12 U.C.L.A. L. REv. 1365 (1965); Pelletier, Shareholder Intent and Congressional Purpose in the Collapsible Corporation Morass, 20 TAX L. Rev. 699 (1965).

188. In Commissioner v. Kelley, 293 F.2d 904 (5th Cir. 1961), the corporation in question had realized one-third of the total net income expected to be derived from its property before it was "collapsed" (the stock sold and the corporation liquidated). The taxpayers claimed that the corporation was not a collapsible corporation within the meaning of the definition in the predecessor to I.R.C. $\$ 341$, which speaks of a corporation " 'formed or availed of *** with a view to the sale or exchange of the stock by its shareholders $* * *$ prior to the realization by the corporation . . of a substantial part of the net income to be derived from [its] property . . .", 293 F.2d at 906 (emphasis added) (footnote omitted) (quoting Internal Rev. Code of 1939, ch. 1, $\S 117(\mathrm{~m})$, as added by Revenue Act of 1950, ch. 994, $\S 212(\mathrm{a}), 64$ Stat. 934). The taxpayers won by convincing the court that "a substantial part" refers to the realized, not the unrealized, portion of the income, and that one-third was substantial. Under this case, the shareholder in note 180 supra could still get the tax treatment described in example III for two-thirds of the expected earnings. See generally Annot., [1977] 3 Stand. Fed. Tax Rep. (CCH) IT 2486.13$.70,2488.10,2490.17-.30$ (1976). 
clear, it is that the consequences of these decisions rarely were foreseen. Though this was no doubt due in part to the impossibility of predicting in full detail the effects of a particular principle, it seems just as evident that no one even made the effort.

Current discussions of tax code revisions display the same error of omission. Reform-minded economists have studied primarily the direct macroeconomic impacts of the present law and proposed changes, with little attention to probable doctrinal ramifications within the legal system. ${ }^{189}$ This inattention to the legal culture per se is unjustified. A system that creates intractable structural tensions and fertile fields for doctrinal development will lead to a substantial amount of expensive "legal noise" in the form of litigation, rulemaking, detailed technical changes in statutes, incessant updating of legal knowledge and advice, and the like. In the economist's own language, each possible reform will produce a corporate tax culture with its own particular bundle of legal transaction costs, and some tax systems may have less costly bundles than others. In the end, achieving the primary economic goals of reform may prove more important than or even inconsistent with lessening the expense, complexity, and ambiguity of the present law. But one should not assume this at the outset, especially given the controversies in the economic literature over the distributive and allocative consequences of the corporate tax. ${ }^{190}$ Careful analysis of the impact of proposed changes on the corporate tax culture may make it

189. See, e.g., note 33 supra (citing sources).

190. For example, the precise manner in which the corporate tax affects the allocation of resources would seem to depend upon who actually bears the burden it imposes. let the incidence question is unresolved. A seminal study by Marian Krzyzaniak and Richard Musgrave indicated that corporations shifted the tax burden to consumers by adjusting prices and that the tax did not induce long-term reallocation of capital from the corporate to the noncorporate sector. M. Krzyzaniak \& R. Musgrave, supra note 33. The study came under extensive attack. See, e.g., Cragg, Harberger \& Mieszkowski, supra note 33 (arguing that Krzyzaniak-Musgrave study failed to include variable for general state of economy, which could be real factor explaining their results); Goode, supra note 33; Slitor, supra note 33. Some analysts have argued forcefully that the shifting issue is irrelevant to the desirability of integrating the corporate with the individual income tax. See, e.g., Mieszkowski, Integration of the Corporate and Personal Income Taxes: The Bogus Issue of Shifting, 31 Finanzarchiv 286 (1972).

In any event, the conventional wisdom among economists seems to be that the corporate income tax is not economically neutral but in some way interferes with the allocation of resources and thereby results in an avoidable loss of welfare. See generally Harberger, Taxation, Resource Allocation and Welfare, in THE Role of Direct and Indirect Taxes in the Federal Revenue System 25-70 (NBER 1964). But see Stiglitz, Taxation, Corporate Financial Policy and the Cost of Capital, 2 J. Pub. Econ. 1 (1973) (arguing that corporate tax is not differential tax on capital in corporate sector, and maintaining that Harberger and others have confused average with marginal cost of capital in their studies). The remainder of this article will assume that the corporate tax burden does fall to some extent upon capital invested in corporations. 
possible to further both goals, or at least to find the best trade-off between direct economic costs and the costs of the legal culture.

Part III attempts to fill the gap left by abstract economic analysis by forecasting the effects that various revisions would induce in the present corporate tax culture. First, it will posit a radical change in each of the seven basic principles in turn and assess the legal consequences of the change on the assumption that all other principles remain intact. Some of the imagined changes will seem familiar; others will seem odd, at least when examined in isolation. All have intriguing doctrinal consequences. The analysis of each change will predict in serial fashion the effects upon the major cultural activities and products explored in Part II: taxpayers' choice of business form; pressures for relief legislation such as subchapter $S$; patterns of allocation of resources and distribution of the tax burden; use of the retained earnings strategy; disguises of dividends; simple bailouts and tensions in the treatment of liquidations, redemptions, and other hybrid transactions; attempts to consummate nonrecognition bailouts; and exploitations of the General Utilities principle. Next, Part III will present and analyze in the same fashion one combination of changes that offers great promise as a reform package. A complete use of the method of analysis employed in Part III would entail an examination of every logically possible combination of changes in the seven basic principles, but it is neither necessary nor feasible to depict those dozens of alternative tax systems here. The focus throughout will be on tracing the ramifications of each change in the legal culture itself. For the sake of completeness, some rather conventional observations about probable macroeconomic consequences are included.191 But the real concern is to isolate and assess cultural repercussions.

\section{A. Systematic Analysis of Fundamental Changes}

\section{Abolition of the Separate Corporate Tax}

Suppose first that the taxing of income to corporations were abolished and no other basic changes were made. There would be no

191. In addition, the analysis assumes, except where otherwise stated, the present basic relationships among tax rates; that is, a virtually flat corporate rate and a progressive spectrum of individual rates, some higher, others lower than the corporate rate. The analysis also assumes that progressivity is a real, not just a rhetorical, norm of our income tax system. Without this assumption, it could be argued that various techniques in the existing and hypothesized systems for reducing effective tax rates on high-bracket shareholders' corporate-source income below their nominal individual rates are justified as expressions of society's "deep-level" acceptance of the view that strict progressivity is really neither feasible nor desirable. 
"double tax." Shareholders would pay an ordinary income tax on corporate earnings distributed as dividends; the tax treatment of such earnings would be like that for partners or sole proprietors. ${ }^{192}$ The benefits of retaining corporate earnings would be greatly magnified, ${ }^{193}$ for corporate income retained and later realized by shareholders in a stock sale would be taxed only once, at capital gains rates. The corporate form would thus become a more desirable investment vehicle than the partnership or proprietorship. Partners are taxed on partnership income whether or not it is distributed, and for proprietors, who do business without the benefit of a separate legal entity, the question of retention or distribution is moot. ${ }^{194}$

The new principle would mean much less planning, litigation, and rulemaking focused on the choice of business form. All businesses would choose the corporate form unless compelling nontax considerations dictated otherwise. There would be no need for subchapter $S$ or for other legislation designed to ameliorate the harshness of the double tax. There would be no double tax, and in any event a subchapter $S$ corporation would be an inferior choice for the same reason as would a partnership: the taxpayers would forgo the benefits of the retained earnings strategy. This might cause a distorted allocation of resources to the corporate sector, and a distortion of managements' internal financing decisions in the direction of retention of corporate earnings.

The increased impetus to the retained earnings strategy would intensify the efforts of taxpayers to evade the accumulated earnings tax and personal holding company tax provisions and would heighten incentives for the Service to make them efficacious. There might be a resulting increase in the complexity of the provisions. The importance of disguised dividend techniques, however, would diminish. Share-

192. For example, an additional $\$ 100$ of corporate income would produce a total federal income tax burden of $\$ 70$ when distributed as a dividend to a shareholder with a $70 \%$ marginal tax rate, just as an additional $\$ 100$ of business income would produce a $\$ 70$ tax burden to a sole proprietor with the same marginal rate. Under the present system, a current distribution would produce a combined tax burden of $\$ 84.40$ to the corporation and shareholder, even though a sole proprietor would pay only $\$ 70$. See note 43 supra.

193. If the corporation in the preceding footnote employed the retained earnings strategy, the total tax burden under the hypothetical new regime would be $\$ 25-\$ 0$ tax to the corporation and $\$ 25$ to the shareholder when he sold his stock $(\$ 100$, his share of the retained earnings, times $25 \%$, his assumed marginal rate for capital gains). The shareholder would thus save $\$ 45-\$ 70$ minus $\$ 25-$ over a policy of currently distributing corporate income. See note 43 supra. In addition, he would benefit from deferring the shareholder-level tax. Under the present system, the retained earnings strategy would produce a total tax burden of $\$ 61$. See note 81 supra. This represents a saving of only $\$ 23.40-\$ 84.40$ minus $\$ 61-$ over a current distribution policy.

194. See note 24 supra. 
holders and close corporations would have little reason to disguise dividends as salaries, interest payments, and the like, for all would result in the same tax burden: one tax, to the shareholder, at his ordinary income rate. ${ }^{195}$

The consequences of the capital gains, dividend, corporate veil, and nonrecognition principles would be similar to those under the present system. Since capital gains would still be taxed preferentially, the same irresolvable tensions in the redemption and partial liquidation areas would persist; permutations of the simple bailouts and the nonrecognition bailouts would continue. Indeed, the greater reward to successful bailouts under the new first principle ${ }^{196}$ might speed developments in these areas. There would still be a need to devote enormous efforts to making the nonrecognition provisions operational and adapting them to new business practices.

Finally, and perhaps most importantly, eliminating the separate corporate tax would not only fail to ameliorate the unpleasant consequences of the General Utilities principle, but it would also extend them significantly. The shocking tax result of the successful collapsible corporation-the elimination of an ordinary income tax at either the corporate or the shareholder level, and the payment of a mere capital gains tax at the shareholder level-would become a generalized benefit of all bailouts under the new principle. A simple sale of stock for the purpose of cashing in one's share of retained earnings, for example, would produce the same tax result as does the successful collapsible corporation now. ${ }^{197}$ But at present, the collapsible device works only when the value at the corporate level inheres in appreciated corporate property-when it represents future income, not current or retained earnings. The simple and nonrecognition bailouts under the present system do enable a reduction of taxes on retained earnings, but only to the level of the corporate undertax model. ${ }^{198}$ Under the new regime, these bailouts would reduce the tax burden to a level that only the classic collapsible corporation can achieve in the present system. Moreover, the General Utilities principle itself, that distributions in kind

195. Of course, fraudulent disguises would likely persist. The corporation might term a distribution a loan, when the loan in fact will never be repaid, or the shareholder might use or consume company assets for personal purposes without reporting as income the value thus received. In either case, the aim would be to avoid paying any income tax at all.

196. Successful bailouts would produce greater rewards because of the magnified advantage of obtaining capital gains treatment upon the disposition of stock. See note 193 supra.

197. Compare note 193 supra with example III in note 180 supra.

198. See pp. 111-14, 118-30 and notes 81,100 \& 156 supra. 
create no gain or loss to the corporation, would become surplusage in the new system; its rule would be simply a particular application of the new first principle, which implies that a corporation never has taxable income. A Congress horrified by the resulting tax-reduction possibilities for shareholders might well supplement the accumulated earnings tax provisions by enacting new antibailout provisions as complicated as present section 341 . These provisions would throw the corporation and its shareholders into the proprietorship model of taxation under intricately specified conditions, in order to forestall the intentional formation or use of the corporate form for the sole or principal purpose of reducing taxes.

Simply abolishing the corporate tax, then, would have unfavorable overall effects. Although it would decrease activity centered on choice of business form or special relief legislation and would virtually eliminate disguised dividend techniques, it would neither affect the problematic liquidation and redemption areas nor discourage simple and nonrecognition bailout attempts. It would encourage over-retention of earnings and might distort the allocation of resources. Worst of all, it would generalize the tax results of the General Utilities bailout and thus, perhaps, create further incentives to devise simple and nonrecognition bailouts. Both economic analysis and doctrinal prognosis would condemn this simple change.

\section{Abolition of the Shareholder-Level Tax on Distributions}

The distribution principle has several aspects, and there is no one "opposite" version of it. But suppose that corporate distributions, even though out of current or accumulated corporate earnings, were never taxed to shareholders. This, in more traditional language, would create an unlimited "dividends-received exclusion": no dividends would be included in shareholders' incomes. Such an exclusion has occasionally been considered as a means of eliminating the double tax on corporate income, though careful economic analysts have criticized it as a poor way to achieve this goal. ${ }^{199}$

As a formal matter, the change would make the dividend principle meaningless. There is no point in presuming distributions to be out of earnings and profits and in stating which rates apply to them if they are not to be taxed at all. But the most striking result for the legal culture would be the inversion of taxpayer incentives in a number of areas: since dividends would incur no tax, the many schemes for ex-

199. See, e.g., McLure, supra note 32 , at 552-53. 
tracting retained corporate earnings at capital gains rates would become undesirable.

Under the new second principle, choice of business form would be even more important than it is today. At present, the chance to fare better as a shareholder than as a partner or sole proprietor obtains only for higher-bracket taxpayers, who can bail out retained earnings at capital gains rates that, combined with the corporate-level tax, produce a lower total tax burden than would individual marginal tax rates. ${ }^{200}$ But if distributions were not taxed, all investors with marginal tax rates greater than the flat corporate rate would prefer to be shareholders in corporations. All investors with marginal tax rates lower than the corporate rate would prefer to be partners or proprietors unless nontax considerations dictated otherwise; they would continue to utilize subchapter $S$ and press for other relief legislation. Because of the sharp relief to higher-bracket taxpayers, the new principle would foster greater deviations from the progressive rate structure of the individual income tax than does the present system. And because of the magnitude of the holdings of higher-bracket taxpayers, there might follow an excessive allocation of resources to the corporate sector.

At first glance, the new principle might seem to free corporations of any $\operatorname{tax}$ incentives to bias their internal financing decisions, since shareholders would not be taxed regardless of whether earnings were retained instead of distributed. Retention of earnings for tax purposes indeed should vanish; this would relieve current stress on the accumulated earnings tax and personal holding company tax provisions. But as noted below in connection with the capital gains and corporate

200. See note 81 supra (explaining why, under present system, not all investors whose marginal tax rates exceed $48 \%$ would prefer corporate to proprietorship form). To take a specific example, consider a taxpayer with marginal rates of $60 \%$ for ordinary income and $25 \%$ for capital gains. If he employs the corporate undertax model in the present system, his total tax burden for an additional $\$ 100$ of business income is $\$ 61-\mathrm{a}$ tax of $\$ 48$ to the corporation and $\$ 13$, or $25 \%$ of the retained earnings, to the shareholder upon sale of the appropriate amount of stock. This is $\$ 1$ more than he would pay as a proprietor. If one restricts attention to investors whose marginal rate for capital gains is $25 \%$ and ignores the benefits of deferring the shareholder-level tax, only investors with marginal tax rates exceeding $61 \%$ for ordinary income will prefer the corporate to the proprietorship form for tax reasons alone. When the value of deferral (which will vary with the length of deferral and the discount rate) is taken into account, shareholders with marginal rates of less than $61 \%$ may find the corporate form desirable. But the perceived benefits of deferral would have to be extraordinary to excite the interest of those in the lower reaches of the $48 \%-61 \%$ range. Furthermore, as the investor's marginal rate for capital gains rises above $25 \%$, the advantage of the undertax model diminishes and eventually is vitiated.

By contrast, any investor whose marginal rate exceeded $48 \%$ would prefer the tax results of the corporate form to those of a proprietorship were the individual tax on distributions abolished. 
veil decisions, the essence of the problem would persist in inverse form.

Disguised dividend techniques would become a more serious problem under the new principle. Higher-bracket shareholders would attempt to turn the law on its head: they would not wish to disguise dividends as salaries, interest payments, or the like; instead, they would have an incentive to disguise the latter as dividends, since dividend income would be taxed only once at the flat corporate rate, which, to them, would be relatively low. Yet for lower-bracket taxpayers, the incentives would remain as they are now. The Service could be expected to pipe different tunes in the two sorts of cases; this would likely make the law even more complex than it is now. In any event, this consequence is not a neutral one, for even if the ultimate shape of the law were not much more objectionable than the present one, there would still be a costly but quite fruitless period of transition, as litigants and judges tried to formulate rules to govern both kinds of disguises.

Since the capital gains and corporate veil decisions would still exist, it would continue to make a difference whether a shareholder cashed in his pro rata share of the corporation's accumulated earnings by a corporate distribution or by a stock disposition. A sale of stock would normally result in a capital gains tax on all proceeds attributable to the corporation's accumulated earnings. But a simple dividend distribution of the same earnings would result in no tax. Consequently, the shareholder whose corporation had accumulated earnings and who wanted to sell to an outsider would pressure the corporation to pay dividends before he sold. This is precisely the opposite of what he would do now, for the current law favors dispositions over distributions. Given enough would-be sellers, there would be pressure for corporations to bias their internal financing decisions toward payment of dividends. Furthermore, the shareholder who wanted to sell his stock to the corporation, whether in a liquidation, partial liquidation, or redemption, would be anxious to fail to meet the requirements for disposition-type treatment and its resulting capital gains tax, while the Service would be pressing in the opposite direction. This complete reversal of present incentives would perpetuate the irresolvable tensions and confusions in a world of mirror images. Conceivably, the same statutory language relating to redemptions and liquidations could be retained. More likely, the Service would press successfully for changes, for the present law makes it too easy for taxpayers to fail deliberately to meet the test for disposition-type treatment. ${ }^{201}$ The

201. For example, under present I.R.C. $\S 302(\mathrm{~b})(2)$, a redemption, if it is to produce exchange-type treatment, must result in the shareholder's owning less than $80 \%$ of his 
new principle would thus spawn a costly process of doctrinal evolution, without any hope that it would result in a more satisfactory legal pattern. ${ }^{202}$

The nonrecognition provisions would be somewhat less necessary. Since all dividends would be nontaxable under the new principle, special rules for not taxing certain stock dividends and spin-offs would be superfluous. There might, however, arise a need to isolate some stock dividend arrangements as disguised redemptions or "essentially equivalent to redemptions" and as therefore meriting disposition-type tax treatment. And the nonrecognition provisions would still be needed to prevent taxation of exchanges of stock in split-offs, ${ }^{203}$ splitups, ${ }^{204}$ recapitalizations, mergers, and incorporations. But the present nonrecognition bailouts would no longer serve any purpose, for they are designed to extract corporate earnings without incurring ordinary tax liability for dividends.

The consequences of the General Utilities principle would persist. The successful collapsible corporation would still be a desirable tax objective, since a solitary capital gains tax on business income would be significantly lower, for all shareholders, than the flat corporate-rate tax on the same income. In the new system, however, the importance of the difference between sections $341(a)$ and $341(f)$, essentially the difference between the proprietorship model and a normal corporate model of taxation, would be greater than it is now. ${ }^{205}$ This might lead

preredemption share of the equity interest and voting power in the corporation. It would be easy enough for shareholders to keep their redemptions from triggering this test or to spread them over time so that they appeared to be separate transactions. The Service would want to lower the percentage figure in the statute, abolish the attribution rules and $\S 304$, and institute elaborate provisions for integration of transactions under various conditions.

202. Realistically, those who favor a dividends-received exclusion are likely to call as well for stock basis adjustments following payment of the corporate tax. For example, the stock basis might be adjusted upward by the amount of a share's pro rata claim on the after-tax addition to retained earnings; this would mean that there would be no taxable gain attributable to those retained earnings if the share were later sold. But this attempt to harmonize the treatment of dispositions with that of distributions modifies the third aspect of the corporate veil principle-a change ruled out for the present analysis. But cf. pp. 153-62 infra (discussing related change as part of reform package).

203. A "split-off" is like a spin-off, except that the distributee-shareholders not only receive the spun-or split-off company's shares but also surrender some of their old shares in exchange therefor.

204. In a "split-up," the two or more businesses of the old corporation are all transferred to subsidiary corporations, and the old corporation, now a mere holding company, is completely liquidated.

205. The tax treatment of collapsible corporations under I.R.C. $\S 341$ (a) produces a total tax burden of $\$ 70$ on income of $\$ 100$. If $\S 341(f)$ is applied instead, the tax burden is $\$ 61$. See note 180 supra. The difference, obviously, is $\$ 9$. In the new system, throwing a collapsible corporation into the proprietorship model would produce a tax burden of $\$ 70$, but allowing it the lowest legitimate tax treatment for corporations would produce a burden of $\$ 48$. The difference now is $\$ 22$. 
to further changes in the complex provisions governing collapsible corporations.

An unlimited dividends-received exclusion would thus have some good consequences. It would abolish the retained earnings strategy (plus the accumulated earnings tax and personal holding company tax provisions and their lore) and would eliminate the incentive for most of the nonrecognition bailouts. It would make no improvement with respect to subchapter $\mathrm{S}$ developments and the progeny of the General Utilities principle; indeed, it might further complicate the tax treatment of the latter. And it would have several bad consequences: accentuation of the importance of choice of business form; untoward allocative and distributive effects; and the starting of new, futile, but costly lines of doctrinal development by reversing the position of the taxpayers and Service in the disguised dividend, liquidation, partial liquidation, redemption, and bootstrap acquisition areas. Again, abstract economic analysis and prediction of doctrinal developments point toward the same result. Adopting the exclusion would hardly seem wise. Even worse would be a system creating a partial or "limited" dividends-received exclusion, for it would contain the undesirable features noted above as well as those of the present system.

\section{Abolition of the Capital Gains Preference}

Suppose capital gains were taxed at the same rates as ordinary income, and capital losses were treated as ordinary losses. The most obvious impact is that shareholders could not avoid double taxation of corporate income at ordinary income rates by selling stock to get the value of their share of retained earnings. All corporate earnings would be taxed on the corporate overtax model. ${ }^{206}$ The only point of the retained earnings strategy would be to defer part of the tax burden. ${ }^{207}$ The double tax would thus bite more deeply; attempts to evade it would be redoubled; and yet, by definition, there could be no bailouts.

Problems connected with the choice of business form would intensify. Many businesses are strongly pressured to seek the nontax advantages of the corporate form, but under the new system, that form

206. See note 43 supra.

207. That deferral would be the only remaining tax benefit might mean that the desire for deferral would become much greater and that shareholders would press more persistently for retention of earnings. If so, the problem of "locked-in" corporate earnings would be aggravated. See pp. 104-05 supra. This observation applies whenever a reform package would reduce the benefits of the retained earnings strategy to "mere" deferral. 
would have farther-reaching and more certain tax disadvantages than at present. For the same reason, there would be greater pressure for relief legislation of the subchapter $S$ type, and more daring attempts to fit nonqualifying corporations under such provisions. Any distorted allocation of resources away from the corporate sector would be aggravated, as would the horizontal and vertical inequities of the present system. ${ }^{208}$

The retained earnings strategy and attendant accumulated earnings tax and personal holding company tax provisions would diminish in importance, for unnecessary retention of earnings would do no more than defer the shareholder-level tax. Conversely, disguised dividend techniques would become more important than ever, and legal developments in the area would accelerate.

The most obvious positive consequence of abolishing the capital gains preference is that it would take the wind out of bailout devices. Since converting ordinary income into the same amount of capital gain would not lower one's tax rate, simple bailout techniques would have much less point. But tax incentives for preferring stock dispositions over distributions would remain, because the different computational procedures would result in different amounts of taxable income under each model. Under the corporate veil decision, proceeds of stock sales and dispositions treated as stock sales are first allocated to nontaxable recovery of the stock's basis. Under the distribution principle, distributed amounts are first treated as coming out of corporate earnings and profits and to that extent are fully taxable. Frequently, situations would arise in which the shareholder would prefer selling part of his stock to receiving a dividend. ${ }^{209}$ If the corporate veil decision were not

208. "Vertical inequity" refers to the practice of taxing corporate-source income differently than other income at the shareholder level. "Horizontal inequity" refers to the dissimilar tax treatment of two taxpayers with equal amounts but different sources of pretax income. That efficient markets discount for taxes, so that investments of equal risk tend to produce equal after-tax rates of return, mitigates horizontal inequity in the long run, but only for investors who purchase after the discounting process has occurred.

209. Consider $X$ Corporation with the following tax balance sheet:

\begin{tabular}{lrlr} 
& \multicolumn{2}{c}{ Liabilities } \\
Cash & $\$ 150$ & Legal capital & $\$ 200$ \\
Other assets & 150 & Earnings and profits & 100
\end{tabular}

The sole shareholder $(S)$ has a total stock basis of $\$ 200$. The corporation's business could relinquish $\$ 60$ of the cash and still operate efficiently. $S$ wants $\$ 60$. If he caused $X$ to pay a $\$ 60$ dividend, he would pay an ordinary income tax on the entire amount, as required by the distribution principle. See I.R.C. $\$ \S 316(a) ; 301(a),(b)(1)(A)$, (c). If he sold $20 \%$ of his stock for $\$ 60$, his taxable gain would be only $\$ 20$-the $\$ 60$ of proceeds minus the $\$ 40$ basis in the stock sold $(20 \%$ of the total stock basis of $\$ 200)$. Under the new system, the $\$ 20$ gain would be taxed at ordinary rates, but the shareholder would 
changed along with the capital gains decision, the Service would attempt to curtail the benefits of "recovery of basis first" by making it difficult for redemptions and liquidations to qualify for sale-type treatment and by treating them solely as distributions if they did not qualify. Thus, tensions in the redemption and liquidation areas would persist, though perhaps not in their currently aggravated form.

The nonrecognition bailouts would become entirely fruitless upon elimination of the capital gains preference. Similarly, the collapsible corporation device would be pointless and section 341 unnecessary. The value of the appreciation in assets held by the collapsible corporation would be taxed at ordinary income rates upon liquidation or sale of the stock, and the scheming shareholders, even if not attacked under section 341 , would have succeeded only in avoiding the double taxation of corporate-source income-a result they could achieve by not bothering to incorporate at all. ${ }^{210}$ Hence, taxpayers would not form

certainly prefer a computational procedure that reduces the amount of taxable income from $\$ 60$ to $\$ 20$.

This advantage would disappear if $S$ extracted the total value of his investment in the corporation. If he sold all his stock, the gain would be $\$ 100(\$ 300$, the value of the underlying assets, minus the total stock basis of \$200) which would be taxable in the new system at ordinary rates. If the corporation liquidated and the event were given sale-type treatment, the result would be the same. But even if the corporation liquidated and the event were treated as a pure distribution, the shareholder would still have taxable ordinary income of $\$ 100$, since there was only $\$ 100$ of earnings and profits out of which distributed amounts could be deemed to come.

Moreover, the preference for stock dispositions would be reversed for individual shareholders under certain conditions. For example, suppose $X$ 's tax balance sheet were as follows:

\begin{tabular}{lr}
\multicolumn{2}{c}{ Assets } \\
Cash & $\$ 150$ \\
Other assets & \\
Cost & 150 \\
Fair Market Value & 350
\end{tabular}

\begin{tabular}{lr}
\multicolumn{2}{c}{ Liabilities } \\
Legal Capital & $\$ 300$ \\
Earnings and profits & 0
\end{tabular}

50

$S$ has a total stock basis of $\$ 300$ and wishes to obtain $\$ 100$ in cash. If he sold $20 \%$ of his stock for $\$ 100(20 \%$ of the company's total market value of $\$ 500)$, he could offset $\$ 60$ $(20 \%$ of his total stock basis of $\$ 300)$ and report $\$ 40$ of taxable gain. By contrast, a simple distribution of $\$ 100$ of cash from $X$ to $S$ would produce no taxable income, for there are no earnings and profits; the entire $\$ 100$ would simply reduce $S$ 's stock basis. $S$ 's preference for a distribution in this example results from the general income tax law's realization requirement: the mere appreciation in value of $X$ 's "other assets" does not produce "income" that is taxed to $X$ and reflected in its earnings and profits account.

210. If the whiskey dealer in note 180 supra had successfully "collapsed," as in example III of the hypothetical, his gain of $\$ 100$ would have been taxed under the new system at his ordinary marginal rate, producing a total tax burden of $\$ 70$. This is $\$ 14.40$ less than the $\$ 84.40$ that the corporate overtax model would exact-a result not changed in the new regime. But it is no better than the burden of $\$ 70$ that the whiskey dealer would have borne had he simply handled the purchase and sale as part of the regular business of his proprietorship. See note 180 supra (example I).

If the whiskey dealer were already doing business through a legitimate corporation, he could still avoid the double tax pattern by having the corporation replace cash dividends with distributions in kind of appreciated property, whenever this was feasible as a business matter. 
corporations solely to take advantage of the General Utilities principle. But the principle would still be useful for existing, legitimate corporations holding appreciated property. Distributing such property instead of selling it and distributing cash would still evade the double tax. Problems stemming from this aspect of the General Utilities principle would persist, along with the related statutory provisions ${ }^{211}$ and case law glosses.

The overall consequences of abolishing the capital gains preference present a mixed picture. The change would increase the importance of choice of business form, generate new pressures for relief legislation, render the corporate form more disadvantageous and inequitable, and increase efforts to disguise dividends. But it would reduce stress on the accumulated earnings tax and personal holding company tax provisions and, most importantly, would greatly diminish incentives to use or invent various bailout devices, even though it would not completely eliminate the tensions in the liquidation and redemption areas and the problems generated by the General Utilities decision. Simply eliminating preferential treatment for capital gains, then, is not a clearly desirable reform. It is important to remember, however, that the predictions above assume that no other changes in the basic principles have been made ${ }^{212}$ and that they pertain only to the desirability of the change for the corporate tax culture.

\section{Taxation of Dividends at Capital Gain Rates}

Suppose the dividend principle were changed by declaring that corporate dividends were henceforward to be taxed at capital gains rates. The most obvious effect would be that shareholders could get the benefits of the corporate undertax model without employing the retained earnings strategy. Their shares of the corporation's after-tax earnings would be taxed at capital gains rates whether realized in a stock sale or received as dividends. The only benefit of earnings retention would be deferral of the shareholder-level tax. Even the corporation that currently distributed all its earnings as dividends would produce, for high-bracket taxpayers, a tax burden less than that of a comparable partnership or sole proprietorship. ${ }^{213}$

211. I.R.C. $\S \S 311.336 .337$.

212. Cf. pp. 153-62 infra (discussing abolition of capital gains principle in contion with other basic changes).

213. The high-bracket investor operating as sole proprietor or partner would pay a $\$ 70$ tax on each additional $\$ 100$ of earnings. If operating in corporate form under the new principle, he would pay only $\$ 61$, and there would no longer be two different corporate models ("overtax" and "undertax"). See notes 43, 45 \& 81 supra.

Investors with marginal tax rates of $58 \%$ or less would still prefer the tax treatment of 
Under such a system, choice of business form would remain a live problem, though more high-bracket shareholders-those wanting current dividends, as well as those content with increases in stock valueswould prefer the corporate form. Subchapter $S$ too would persist and would continue to generate problems, since lower-bracket investors would still be attracted to that vehicle. More resources might be allocated to the corporate sector, for the change would lessen the burden of double taxation. This would be advantageous if it is indeed true that the existing system unduly diverts resources from the corporate sector, ${ }^{214}$ for the new effect would offset such distortions to some extent. Internal financing decisions would remain biased toward retention of earnings, but only to the extent that taxpayers expected net benefits from the deferral of taxes; the accumulated earnings tax and personal holding company tax provisions would become correspondingly less important and less troublesome. Equity problems would be similar to those of the present system. ${ }^{215}$

The new principle would encourage high-bracket shareholders to disguise salaries and interest payments as dividends, for the same reason discussed in connection with the hypothetical elimination of the entire shareholder-level tax on distributions. ${ }^{216}$ Lower-bracket shareholders, however, would continue to disguise dividends as other things. The law would become more confusing and uncertain.

The tensions generated by the present antithetical principles invoked by hybrid transactions would abate, and attempts to achieve simple bailouts would subside. Both distributions and dispositions would produce capital gains taxation for the shareholder. But under the new principle, as in a system without the capital gains preference, individual shareholders still might prefer disposition-type treatment to distribution-type treatment, because the computational procedures mandated by the corporate veil decision often would produce a lower amount of gain. ${ }^{217}$ Thus a body of law specifying conditions for treating redemptions and liquidations as dispositions would remain, but it would be less important and perhaps less complex.

the proprietorship or partnership form to that of the corporation. Investors with marginal rates between $48 \%$ and about $61 \%$ would find the new tax aspects of the corporate form attractive only if they wished to defer the individual tax by retaining earnings. Frequently, however, this deferral value would be outweighed by the difference between these individuals' comparatively low marginal tax rates for ordinary income and the sum of the corporate rate and individual capital gains rates.

214. See note 190 supra.

215. See note 208 supra.

216. See pp. 141-43 \& note 200 supra.

217. See pp. 145-46 \& note 209 supra. 
Nonrecognition bailouts would lose all purpose. The consequences of the General Utilities principle, however, would persist in even more offensive form. Taxpayers could achieve the tax objectives of the collapsible corporation device without selling stock and without liquidating their corporations. Any distribution of appreciated inventory or similar property would avoid imposition of an ordinary income tax at either level and would produce only a capital gains tax at the shareholder level. Undoubtedly, the Service would seek statutory weapons against distributions in kind motivated solely or principally by tax considerations. The tumorous convolutions of section 341 might metastasize to all provisions involving distributions.

Taxing dividends at capital gains rates thus would have the adverse consequences of complicating the disguised dividend area and generalizing the tax reduction opportunities of the General Utilities principle. But its effects on the choice of business form and the demand for special deals like subchapter $S$, as well as its overall allocative and distributive consequences, seem relatively unimportant. Moreover, it would have very good effects in curtailing the retained earnings strategy and thereby in relieving the need for the accumulated earnings tax and personal holding company tax provisions, damping incentives to exploit simple bailout devices, reducing tensions in the redemption and liquidation areas, and abolishing attempts at nonrecognition bailouts. This is a surprisingly favorable balance sheet for a proposal that seems never to have been taken seriously. Quite probably, it is the conceptual dissonance of likening dividend payments (which are clearly fruit of the tree) to proceeds of the sale of a capital asset (the tree itself) that has hampered analysis of this idea. And some analysts may have realized that other changes ${ }^{218}$ would achieve the good consequences of this new principle in a more complete way.

\section{Making Stock Dispositions Dependent on Corporate-Level Attributes}

The corporate veil principle could be changed in various ways. One alternative would be to declare that stock is not a capital asset, so that gain from its sale produces ordinary income. The consequences of this move would be similar to those of abolishing the capital gains preference entirely. A more interesting alternative to the veil decision is to harmonize the tax treatment of stock dispositions with that of distribu-

218. See pp. 153-62 infra. 
tions by basing it on corporate earnings and profits accounts associated with each share. The discussion of the veil principle in Part II explored the mechanics of this alternative world.219 In such a system, stock sales and simple bailout devices would not outflank the corporate overtax model of taxation, ${ }^{220}$ and artificial retention of earnings would only defer the individual tax. Obviously, the administrative costs of basing the tax treatment of stock dispositions upon corporate-level bookkeeping would be enormous. To offset these costs, benefits would have to be quite substantial.

The greater incidence of double taxation at ordinary rates would result in an exodus from the corporate form, a move, no doubt, that nontax considerations would block for many large companies. The demand for special provisions such as subchapter $S$ would be intensified. A greater misallocation of resources away from the corporate sector would likely ensue.

Deferring taxes through retention of earnings would remain a useful technique, and the legal weapons against such delay would persist. Pressures to disguise dividends would be more intense: although the amount of potential tax avoidance would be the same, there would be fewer alternatives for reducing taxes. The simple bailouts would be useless, for the computational procedures for dispositions and distributions would yield identical amounts of ordinary income or capital gains. This would ameliorate present difficulties in classifying hybrid transactions for tax purposes. The nonrecognition bailouts would be equally pointless if appropriate technical rules were adopted. Upon distribution of nontaxable stock dividends, for example, amounts from the earnings and profits accounts attributable to the stock on which the dividend was declared would have to be allocated to the dividend shares, in order to create earnings and profits accounts for the latter. Otherwise, the sequence of events in the preferred stock

219. See pp. $108-10$ \& notes 77-80 supra.

220. In the new system, proceeds from sales of stock would first reduce earnings and profits accounts; they would be taxed as ordinary income to the extent of those earnings and profits. See pp. 108-10 and notes 78 \& 79 supra. The high-bracket investor employing the retained earnings strategy and cashing in his share of retained earnings by selling stock would thus bear a total tax burden of $\$ 84.40$ on each additional $\$ 100$ of pretax corporate income allocable to his shares-a $\$ 48$ tax to the corporation and a $\$ 36.40$ individual tax on the remainder $(70 \%$ of $\$ 52)$. C f. notes 43 \& 81 supra (illustrating present corporate overtax and undertax models). If sales proceeds exceeded the sum of corresponding earnings and profits plus the amount of the seller's basis in the stock sold, the excess would be taxed at capital gains rates. (The excess would generally be due to unrealized corporate-level income, i.e., appreciation in value of corporate assets.) The same benefit now obtains for distributions that exceed the sum of the stock's pro rata share of earnings and profits and the stock's basis. See I.R.C. § 301 (c). 
bailouts could still reduce taxes. ${ }^{21}$ Similar points apply to corporate divisions and to receipt of debt securities in a recapitalization or merger. These technical adjustments would add to the administrative costs of the new system.

Collapsible corporations would still be attractive devices. The realization requirement and the General Utilities principle would prevent addition of appreciation in asset values to earnings and profits accounts. Hence, such gains would still qualify for capital gains treatment upon "collapse" by liquidation or stock sale, unless section 341 were applied. Other consequences of the General Utilities principle would persist as well, since existing, legitimate corporations would still have an incentive to distribute rather than sell appreciated property.

The most favorable consequences of the hypothetical change in the corporate veil decision would be the elimination of simple and nonrecognition bailouts, but these would have to be balanced against substantial administrative costs and, arguably, against further misallocation of resources. It would leave intact or mildly aggravate problems associated with choice of business form, subchapter $\mathrm{S}$, retention of earnings, disguised dividends, and the General Utilities principle. The consequences as a whole seem not to promise distinct improvement.

\section{Abolition of Nonrecognition Provisions}

Assume the most extreme of conceivable departures from the nonrecognition principle: no nonrecognition provisions other than those excepting undistributed corporate income from the shareholder-level tax. This radical rule would obviate the considerable efforts now expended in applying the nonrecognition provisions and in adapting them to changing business practices. It would eliminate most ${ }^{222}$ of the nonrecognition bailouts. Hence the rule might increase incentives to disguise dividends, retain earnings, and employ simple and General Utilities bailouts, in order to clear corporations of earnings before

221. See pp. 119-20 supra. If portions of existing earnings and profits were not allocated to the nontaxable dividend stock, proceeds from its sale would first reduce its basis, and the excess would be capital gain. By contrast, a cash dividend on preexisting stock would be deemed to come first out of the stock's earnings and profits accounts (and to that extent would be treated as ordinary income), as would proceeds from the sale of such stock. Consequently, stock dividends would be used to reduce taxes in the new system, unless the suggested technical rule, or some other weapon, were adopted.

222. Abolishing nonrecognition provisions would render useless preferred stock bailouts, see pp. 119-20 supra; divisive bailouts, see pp. 121-23 supra; and security bailouts, see pp. 123-24 supra. But some liquidation-reincorporation schemes would still be worthwhilc. See pp. $125-27$ and notes $156 \& 157$ supra. 
major organic changes such as mergers, which today are nontaxable. The remaining doctrinal landscape should change very little under the new rule. The effects of the nonrecognition principle are more isolable than those of the earlier decisions.

Such a proposal, however, would raise an important issue of economic policy. Abolishing nonrecognition provisions without changing other principles would erect a substantial tax barrier to major changes in business form, such as midstream incorporations of existing businesses, mergers, recapitalizations, and corporate separations. Such changes can serve legitimate and important business purposes, and hindering them could be economically undesirable. This large but separable issue need not be pursued here.

\section{Reversal of the General Utilities Principle ${ }^{223}$}

Suppose that all corporate distributions of appreciated property gave rise to corporate income, taxable at ordinary or capital gains rates depending on the nature of the property. The intricate rules now governing such distributions would not exist, and there would be no need for provisions preventing recognition of corporate gain or loss from sales of corporate assets following adoption of a plan of liquidation. The exemptions and judicial accretions to those provisions would likewise disappear. There would be no General Utilities bailouts and no collapsible corporations. Monstrous section 341 could be repealed. These consequences would be good ones; they would streamline the legal culture and muffle some expensive "noise" in the system.

Remarkably, the new principle would have very little impact on consequences stemming from the first six basic principles. The General Utilities principle, like the nonrecognition rules, has fairly isolable effects. One exception is that the insistence on two-level taxation of appreciated property would hinder cash sales of corporate businesses, or at least create a bias for stock sales, and would thus encourage more taxpayers to seek the benefits of the reorganization provisions and perhaps to play fast and loose with those provisions. But, in general, reversal of the General Utilities principle is a reform measure that is hard to fault and that, unlike the other changes discussed above, makes very good sense when enacted by itself.

223. The consequences of reversing the General Utilities principle were analyzed in superb fashion in Lewis, $A$ Proposed New Treatment for Corporate Distributions and Sales in Liquidation, in 3 Staff of House Comm. on Ways and Means, Tax Revision Compendium, 86th Cong., 1st Sess., 1643 (Comm. Print 1959). Similar insights appear to underlie Professor Wolfman's unusual move of beginning his casebook with the General Utilities case. B. Wolfman, Federal Income Taxation of Business Enterprise 5 (1971). 
B. A Promising Package: Thorough Integration, Abolition of the Capital Gains Preference, and Reversal of the General Utilities Principle

Although superficial thought might suggest that one could undo the existing problems of the corporate tax culture simply by abolishing the corporate tax, the preceding analyses of isolated changes should have demonstrated what the reflective reader will long have suspected: effective reform requires more radical change. None of the basic changes hypothesized above would alone solve all current problems within the corporate tax culture, and only one-reversal of the General Utilities principle-would have no major doctrinal disadvantages. Apparently, radical simplification or improvement of the corporate tax culture is to be accomplished, if at all, by changes in more than one of the basic decisions.

The remainder of the article applies this lesson by positing a combination of changes in the basic principles of the corporate tax culture and tracing the consequences. The composition of the chosen package is premised upon a simple intuition: to effect permanent improvement in the present law, one must effect fundamental changes in each set of basic principles-the double tax set (the separate tax and distribution principles), the capital gains set (the capital gains, dividend, and corporate veil principles), and the nonrecognition set (the nonrecognition and General Utilities principles). The combination analyzed below radically alters the first set and modifies the veil principle by applying to corporations an integration scheme similar to that now used to tax the capital gains income of regulated investment companies. ${ }^{224} \mathrm{~A}$ related scheme has already been proposed in the justly celebrated Canadian study by a group known as the Carter Commission. ${ }^{25}$ To defuse more thoroughly the bailout opportunities that stem from both the second and third sets, the package abolishes the capital gains preference. Finally, the package reverses the General Utilities principle to eliminate its largely undesirable consequences. ${ }^{226}$

The rationale of this approach to reform appears deceptively simple. To find a combination of changes that would unravel most of the existing corporate tax culture without breeding unforseeable new complexities is a difficult riddle. If the answer to the riddle can be

224. I.R.C. $\$ 852(\mathrm{~b})(3)$. $s \rightarrow$ Clark, The Federal Income Taxation of Financial Intermediaries, 84 YALE L.J. 1603, 1624-28 (1975).

225. Report of the Royal Commission on Taxation (1966) (Canada).

226. The general nonrecognition provisions are left intact, partly because their abolition might be economically undesirable, see p. 152 supra, partly out of deference to the general income tax law's realization requirement. 
seen in the reform package that follows, it is only because we are, in Newton's phrase, "standing on the shoulders of giants." 227

Suppose that corporations were taxed somewhat like partnerships, but with provisions for withholding taxes at the corporate level. Currently distributed earnings would be taxed only to the shareholders, at their individual marginal rates for ordinary income. Undistributed current earnings could be "allocated" to shareholders by fiat of the corporation. Allocated earnings would not be taxed separately at the appropriate corporate level; rather, the corporation would pay a withholding tax on such earnings, at the highest marginal rate applicable to individuals. The shareholders would receive notices describing their pro rata shares of the allocated income and the taxes withheld. Shareholders in the highest marginal tax bracket would pay no further tax on allocated income. Other individual shareholders could claim refunds equal to the difference between the tax withheld by the corporation and the tax actually due (determined by multiplying their shares of the allocated income by their particular marginal tax rates). The immediate-refund feature would provide an incentive for the corporation to allocate retained earnings. When it could not feasibly do so (because of a complex capital structure, for example), it would pay a tax, at the highest individual marginal rate, on earnings not currently distributed or allocated. ${ }^{228}$ If the retained but unallocated earnings were eventually distributed, the shareholder-recipients would be treated as though they had received both the distributed amount and the associated tax previously paid by the corporation, but would receive a credit for the tax paid by the corporation. Shareholders not in the highest bracket would then receive a refund (but no compensation for its deferral).

After an allocation of undistributed income, each shareholder's basis in his stock would be adjusted upward by the amount of his pro rata share of the allocated income less his pro rata share of the taxes with-

227. See generally R. Merton, ON THE Shoulders of Giants (1965) (erudite historical account of phrase, suggesting great importance of cumulative, interrelated advances in human knowledge).

228. The description of the integration technique in the text focuses only on individual shareholders and shareholders that are trusts. Corporate shareholders raise problems that cannot be explored in adequate detail here. One simple approach would be to require corporate shareholders, whether or not they control the companies in which they hold stock, to treat amounts distributed or allocated to them as part of their income from operations and thus as eligible for integrated treatment with respect to their own shareholders. "Pass-through" taxation would thus extend through any number of tiers of corporations, until individuals finally were taxed. This approach rejects the view that there is a sufficient reason (such as the undesirability of corporate pyramids) for the tax law to penalize intercorporate distributions. 
held. This adjustment would ensure that retained, allocated, and thus already taxed income would not be taxed again should a shareholder later sell his stock at a price reflecting these retained earnings. The adjustment modifies the corporate veil decision but would entail far smaller administrative costs than the one already discussed. ${ }^{229}$

The general effect of the changes thus far would be to make corporations taxable in the same way as partnerships, except that a withholding system would be instituted to ease the difficulties of collecting a shareholder-level tax on undistributed income, and a separate corporate tax would persist for corporate income that remained undistributed and unallocated. Now suppose further that the capital gains principle were abolished.

All business forms would bear essentially identical tax burdens. This would reduce the significance of choice of business form and would render subchapter $S$ unnecessary. The macroeconomic consequences would seem ideal, for the greater equality of taxation among various business forms would mean, all other things being equal, little misallocation of resources into or out of the corporate sector. Nontax business considerations could thus take precedence. Furthermore, there should be no disharmonies within the progressive rate structure applied to individual taxpayers, since corporate-source income would in most cases be taxed at each individual shareholder's personal rate. The triad of tax models (corporate overtax, proprietorship, and corporate undertax) would be reduced to one.

The resulting model would eliminate incentives to disguise salaries,

229. For a numerical illustration of the entire procedure, consider the standard corporation and shareholder of note 43 supra. The corporation earns an additional $\$ 100$, distributes $\$ 48$ as a dividend to the shareholder, then "allocates" to his stock the retained $\$ 52$. The $\$ 48$ is taxed only once, to the shareholder, at his $70 \%$ marginal rate: the tax paid is therefore $\$ 33.60$. The corporation pays a withlolding tax of $\$ 36.40(70 \%$, the highest marginal rate for individuals, times $\$ 52$, the allocated retained earnings). The shareholder receives a notice that he must report a constructive dividend of $\$ 52$ on his tax return but can take credit for the $\$ 36.40$ paid by the corporation. Since $\$ 36.40$ is exactly his tax liability for the constructive dividend, the credit exactly offsets his tax liability for that dividend. The total tax on the additional $\$ 100$ of corporate income is thus $\$ 33.60$ plus $\$ 36.40$, or $\$ 70$. This is exactly the total that this investor would pay if he operated as a partncr or sole proprietor, and the equivalence will hold true for every lower-bracket taxpayer. The shareholder with a 50\% marginal rate, for example, would pay a $\$ 24$ tax on his real dividend of $\$ 48$. His tax liability on the $\$ 52$ constructive dividend would be $\$ 26$. His tax credit would still be $\$ 36.40$, the amount paid by the corporation, and he would receive a refund of $\$ 10.40$. The total tax burden would be $\$ 50 ; \$ 24$ plus $\$ 36.40$, minus $\$ 10.40$.

In each case, the shareholder's claim on retained earnings is reduced by $\$ 36.40$, the amount paid by the corporation as a withholding tax. To prevent the retained but allocated earnings from being taxed again should the shareholder sell his stock, the stock basis is then increased by $\$ 15.60$ (the $\$ 52$ of retained earnings minus the withholding tax of $\$ 36.40$ ). 
interest payments, and the like as dividends, or vice-versa, for all would be taxed in the same manner. This beneficial effect would not depend on whether the shareholders were in high or low tax brackets. The provisions for withholding taxes on retained but allocated earnings would vitiate the tax advantages of retaining such earnings and thereby would obviate in great part the accumulated earnings tax and personal holding company tax provisions. Simple bailout devices would be partially eliminated, for the stock basis adjustments following allocation of retained earnings would reduce the present tensions resulting from differential treatment of distributions and dispositions. Since retained but allocated earnings would be taxed at once and would incur no further tax whether actually distributed or cashed in by disposition of stock, there would be, with respect to allocated earnings, no tax advantage in resorting to a stock sale, redemption, or partial liquidation instead of a distribution.

Two problems, however, would remain. The first and less important is that of realized corporate earnings that might be retained but not allocated. A stock disposition often would produce gain attributable to these earnings, and any such gain would be subjected to a double taxthe corporate tax on the unallocated retained earnings plus an ordinary income tax to the shareholder upon sale of his stock. The rule for basis recovery in stock dispositions would mitigate the impact of this second tax by reducing the taxable gain to an amount significantly below the shareholder's pro rata share of the corporation's post-tax retained but unallocated earnings. Yet a distribution of the same earnings would produce no tax, or even a refund, to the shareholder. This would at least eliminate any remaining need for the accumulated earnings tax and personal holding company tax provisions, which are designed to prevent tax avoidance through retention of earnings. But the tax discrepancy between distributions and dispositions, which has proved so troublesome in the present system, would persist in inverse form. In the new system, however, this problem should have few objectionable practical effects, at least for retained but unallocated earnings. No principle would mandate double taxation; that taxpayers might choose to avoid a double tax by employing distributions instead of stock sales would thus be unobjectionable. And in any event, the immediate-refund advantage of the allocation technique would motivate taxpayers to arrange capital structures and other variables to ensure allocation of retained earnings and thus would moot the problem. $^{230}$

230. Recall that the tax rate applied to all retained earnings, whether or not allocated, was set at the highest marginal rate for individuals. Hence, if a corporation retained but 
The second and more important remaining problem is that of unrealized appreciation in the value of corporate assets. Because the reform package would not abolish the realization requirement of the general income tax law, unrealized gains would not produce income at the corporate level. This, no doubt, would prompt taxpayers to invent schemes for realizing such gains at the shareholder level through transactions that qualify for disposition-type treatment. The purpose, of course, would be to exploit the new system's obvious means of reducing taxes-the rule for "recovery of basis first" in dispositions. This could lead to further manipulations of the present bailout devices. ${ }^{231}$

The logical solution is to eliminate the computational disparity between distributions and dispositions. The approach explored earlier, which sets up earnings and profits accounts for each share, is almost certainly unworkable. ${ }^{232}$ Moreover, the problem appears inherently incapable of resolution. In order better to appreciate this important point, consider an alternative means of eliminating the disparate treatment, a means that appears at first blush to be an effective solution: instead of assimilating dispositions to distributions, try to assimilate distributions to dispositions.

Suppose, for example, that the reform package were supplemented by reversing the second aspect of the dividend principle-that distributions presumptively come first out of the corporation's earnings and profits. In its place would stand a new principle:

The constructive stock sale rule. Every distribution from a corporation to a shareholder in his role as shareholder shall be treated as a sale of part of his stock to the corporation. The percentage of shares deemed sold shall equal the ratio between the amount distributed to the shareholder and the predistribution value of his shares.

The basic insight behind this approach is simple. Shares of stock may be viewed as residual claims against company assets, rather than as pieces of paper (stock certificates). A corporate distribution of assets, whether in cash or in kind, affects these claims. The result can be described in either of two ways. One could assume that the number of

did not allocate earnings, its highest-bracket shareholders would not benefit, and all cther shareholders would lose a current refund. Accordingly, corporations would be under pressure to simplify their capital structures so that allocations could be made. In this respect, the new system might have a distorting effect on business decisions.

231. The purpose of all the bailouts described in Part II is, by definition, to extract corporate earnings at capital gains rates. See p. 105 \& note 13 supra. This requires disposition-type tax treatment. "Recovery of basis first" is an additional benefit that does not depend on the capital gains preference.

232. See pp. 108-10 supra. 
claims is fixed, and say that the distribution decreases their values. Or one could assume that the value of each claim is fixed, and say that the distribution decreases the number of claims.

A constructive stock sale rule would be based on the latter conceptualization. If, for example, a dividend equal to ten percent of the corporation's assets were distributed to shareholders, then ten percent of each shareholder's stock would be deemed to have been sold back to the corporation. ${ }^{233}$ To avoid complications caused by elaborate capital structures, the rule would focus on individual shareholders; it would use the market value of their holdings to calculate the percentage of stock deemed sold and would allow separate treatment for distributions on different classes of each one's stock. If a shareholder had 100 shares of common stock worth $\$ 100$ and received a $\$ 10$ dividend, he would be deemed to have sold ten percent of his common shares to his company. Hence, the $\$ 10$ would first be applied against his basis in those shares. Any excess would be considered ordinary taxable income because of the abolition of the capital gains preference, and any shortfall would be ordinary loss. Such a rule would raise various technical problems that might readily be solved. ${ }^{234}$ Under its aegis, distributions and dispositions for equal values would produce equal amounts of reportable gain for shareholders. ${ }^{235}$ The equivalence

233. A roughly analogous approach appears in I.R.C. $\$ 305(\mathrm{c})$, which in effect permits the Service to find constructive stock dividends.

234. For example, in a pure distribution, actual stock certificates are not relinquished by shareholders. This would create problematic tax-deferral opportunities if the basis reduction were applied only to the shares by which it was measured. The rule would therefore have to mandate that the basis reduction be spread among all shares of the affected class of stock held by each individual receiving a distribution. If the basis reduction were not spread among all shares of an affected class, a shareholder might be able to preserve one block of shares with a high basis, which he could sell with minimum tax liability.

235. Suppose that $X$ Corporation has the following balance sheet:

\begin{tabular}{cccl}
\multicolumn{5}{c}{ Assets } & & \multicolumn{1}{c}{ Liabilities } \\
Asset A & cost & market value & \\
Asset B & $\$ 10$ & $\$ 50$ & Legal capital \\
& 50 & 50 & Retained earnings
\end{tabular}

$\$ 60$

The sole shareholder $(S)$ owns 100 shares, each with a basis of 60 cents.

(a) $S$ sells half his shares to an outsider for $\$ 50$. His gain is $\$ 50$ minus $\$ 30$ (the basis of half his shares), or $\$ 20$, which is taxed at his ordinary marginal rate.

(b) Instead of selling half his shares, $S$ causes $X$ to distribute to him as a dividend either Asset $\mathbf{A}$ or Asset B. The amount of the distribution is $\$ 50$. Since the predistribution value of his shares was $\$ 100$, he is treated as if he has sold $50 / 100$ of his 100 shares (i.e., 50 shares) to his corporation. His gain is therefore $\$ 50$ (the amount received) minus $\$ 30$ (the basis of half his shares), or $\$ 20$, which is taxable, as always, at his ordinary marginal rate.

$S$ actually continues, however, to hold all 100 shares. To prevent possible inequities or manipulations, see note 234 supra, the law would require that the $\$ 30$ basis reduction be spread evenly. Each share's basis would therefore be reduced from 60 to 30 cents. 
would obtain automatically, even for distributions in kind. ${ }^{236}$ Hence, a major source of problems-the General Utilities principle-would be mooted. ${ }^{237}$

Unfortunately, however, a constructive stock sale rule would create grave difficulties that outweigh its advantages. Though the rule's administrative costs would be significantly less than those of its alternative, ${ }^{238}$ collecting the necessary data and applying the rule to all distributions would still be expensive. Moreover, while introducing an element of basis recovery into the treatment of distributions would reconcile their treatment with that of dispositions, it would create numerous other discrepancies. Interest payments on debt securities are not offset by any part of the debt's basis; if the rule were not extended to debt securities, investors might therefore try to disguise bonds and debentures as preferred stock. Similarly, unless the rule were extended to allocated but retained income, shareholders would favor actual distributions over allocations. These difficulties might seem palatable, or at least an acceptable price to pay for the benefits of a constructive stock sale rule. But the deeper problem with the rule is that it would reintroduce a discrepancy between the treatment of corporate-source income and income from partnerships or proprietorships. The former, but not the latter, would be regularly offset by some portion of the investor's basis in his investment interest. To attempt to rectify this discrepancy-a more important one, presumably, than that between dividends and stock sales-by applying a variant of the rule to partners

236. See example (b) in note 235 supra.

237. Observe that, in the example in note 235 supra, it makes no difference whether Asset $\mathbf{A}$ (the appreciated asset) or Asset $B$ (the unappreciated asset) is distributed.

Furthermore, if $S$ liquidated $X$ first and then sold the assets for cash, the tax result would be the same as if $X$ had sold the assets for cash and then distributed the proceeds to $S$ in liquidation. In the former case, $S$ would have gain of $\$ 40$ on the liquidation; the basis of Asset A would be stepped up (because the appreciation in value was just taxed); and no further gain would result when the assets were sold at their market value. In the latter case, the asset sale would produce $\$ 40$ of gain to $X$. But, since the $\$ 40$ would be currently distributed, only $S$, under the integration technique, would pay a tax on it. Thus the new system would have no need for $\S 337$, which was designed to harmonize the corporate asset sale-liquidation sequence with the liquidation-stockholder asset sale sequence. See p. 131 \& note 173 supra.

238. Only three data would be needed to operate a constructive stock sale rule: the number of each individual's shares to which the distribution applies, the dollar value of the distribution on those shares, and the predistribution market value of the shares. Workable mechanical rules for implementing the new procedure could easily be devised. For example, one might define "the predistribution market value of shares" as the average of the closing prices of the stock on the 10 business days immediately preceding the date on which the declaration of the distribution was made.

A trust department or shareholder with many holdings might find it annoying to apply the rule to numerous dividends received every quarter. This difficulty could be ameliorated by making the rule elective. Less tractable is the problem of valuing stock in close corporations. 
and proprietors would entail sweeping and costly changes throughout the tax law.

The lesson of this illustration is that the discrepancy between the tax treatments of distributions and dispositions is an instance of a much more general problem. The present income tax law generally prohibits owners of assets of indefinite life (such as bonds, stock, or land) from offsetting recurrent earnings by amortization of basis; basis recovery is permitted only upon sale of the asset. Thus, ground rents are not offset by depreciation or other amortization deductions, but gain upon sale is computed as amount received minus the seller's basis in the land. ${ }^{239}$ Whether it makes sense to allow amortization of the basis of assets of indefinite life, and, if so, what the appropriate amortization formula should be, are general questions that should not be given ad hoc answers in specific areas of the tax law.

Reformists should thus bear in mind that unless one is prepared to embark upon sweeping general income tax law revisions such as abolition of the general realization requirement or overhaul of the treatment of all assets of indefinite life, one must accept some discrepancy between the tax treatments of distributions and dispositions. The thorough integration technique proposed above would confine the problem principally to gains attributable to appreciated corporate assets, and the abolition of the capital gains preference would mitigate it by reducing it to a question only of the amount of income, not of tax rates as well. This may be as much as corporate tax reform can accomplish.

The final addition to the reform package would be a reversal of the General Utilities principle to eliminate its isolable and generally objectionable consequences, particularly the collapsible corporation device and section 341 . This would complete the attack on the present law's most troublesome aspects, for the first two components of the reform combination would remove most of the tensions surrounding simple bailout devices as well as eradicate nonrecognition bailouts. ${ }^{240}$ The nonrecognition provisions would still be needed to prevent taxation of unrealized appreciation in asset values in transactions involving a substantial continuity of ownership interests (for example, certain stock dividends and legitimate reorganizations). These rules would be no more complex than at present; they could not be abolished with-

239. See M. Chirelstein, supra note 61 , at \% 6.07 .

240. The integration technique and associated stock basis adjustments would mean that retained earnings would not produce gain in nonrecognition transactions even if such transactions were taxed. 
out substantial encroachment upon the realization principle of the general income tax law.

The reform package as a whole would thus unravel most of the noxious ramifications of the existing set of basic principles of corporate tax law. It would not eliminate the desire to minimize or evade taxes nor would it alter the behavioral tendencies of the Service, the courts, and Congress. General income tax avoidance strategies, such as fraud or "income-splitting," would thus be likely to continue in the corporate tax area. But careful examination of the package will show that it would eliminate most of the major unique opportunities for tax avoidance that now inhere in the intricate and sometimes internally inconsistent corporate tax culture. Such a combination of reforms offers at least a hope that the processes of cultural evolution will slow and perhaps stop at a more acceptable level of complexity, confusion, and expense. ${ }^{241}$

\section{Conclusion}

The first two parts of this article explored the morphogenesis of the corporate tax, uncovering its roots and tracing the multitude of legal rules and doctrines to the basic principles from which they derive. Part III explored possible metamorphoses of the law-the changes in its form that would result from alterations of the basic principles. The one combination of reforms chosen for analysis represents a provisional attempt to indicate a package of changes that holds promise, not only because of its direct effects on allocative and distributive aspects of the tax system, but also because of its reduction of complexities and structural tensions in the legal culture. The aim has not been to assert definitively how the law should be changed. Rather, it has been to demonstrate the utility of an axiomatic method of analyzing reforms.

The central question implicitly raised is whether human decisionmakers can transcend in a rational and successful manner the blind, unpremeditated processes of cultural evolution. Having become conscious of the laws of development of the tax culture, can we effectively

241. The reform-oriented tax lawyer who looks solely for new and decisively better solutions to present problems may be disappointed with the ultimate conclusion of this article. The reform package discussed in the text consists of elements already suggested by others. The purpose of this analysis, however, is not merely to generate another plan of reform but to establish, in a comprehensive, systematic way, the superior value of one set of changes by reference to a largely neglected consideration-the reform's likelihood of reducing costs within the corporate tax culture. In this essay, the frequent injunction to simplify the whole system has been taken in dead earnest. I have pursued simplification as the Hound of Heaven pursued the poet Thompson. 
improve them? As Part III demonstrates, one can predict methodically the consequences of changing some or all of the basic decisions that underlie the present system. Such an inquiry undoubtedly succeeds better in recapitulating old problems that the contemplated changes would eliminate, aggravate, or leave untouched than in forecasting entirely new problems created by alternative schemes. In law at least, the gift of prophecy is distressingly rare, in part because well-founded predictions are an inadequately subsidized public good. The lawyer's grasp of this reality may account for some of the conservatism of many past studies of corporate tax reform. But part of the problem is surely that policymakers do not usually feel sufficiently certain about the effects of proposed reforms on the entire set of familiar problems. It is hoped that the methods employed in this essay will contribute to a reduction of these uncertainties and, ultimately, to a rational transcendence of the past. ${ }^{242}$

242. A notable current effort at rational transcendence of subchapter $C$ is the American Law Institute project, which recently reached a propitious stage with the publication of its work on corporate acquisitions. ALI, Federal Income Tax Project: Subchapter C (tent. draft no. 1, March 25, 1977). 